\title{
Crosswind Effects on Interaction Performance of High-speed Railway Pantograph-catenary System: A Case Study in Chengdu-Chongqing Passenger Special Railway
}

\author{
Yang Song ${ }^{1}$, Fuchuan Duan²*, Shibin $\mathrm{Gao}^{2}$, Fanping $\mathrm{Wu}^{2}$, Zhigang $\mathrm{Liu}^{2}$, Xiaobing $\mathrm{Lu}^{3}$ \\ 1. Department of Structural Engineering, Norwegian University of Science and Technology, \\ Trondheim, 7491 Norway; y.song_ac@hotmail.com (Y.S.) \\ 2. School of Electrical Engineering, Southwest Jiaotong University, Chengdu, 610031, China. \\ wufanping123@163.com (F.W.); liuzg_cd@126.com (Z.L.); gao_shi_bin@126.com (S.G.); \\ duanfc_cd@outlook.com (F.D.) \\ 3. China Railway Eryuan Engineering Group CO. LTD, Chengdu, 610031; hello.lxb@163.com \\ (X.L.)
}

\section{Abstract}

As a common disturbance to the railway pantograph-catenary system, the crosswind may deteriorate the current collection quality and threat operational safety. The main topic of this paper is to study the effect of crosswind on the interaction performance of pantograph-catenary considering the aerodynamic forces acting on both the pantograph and catenary. The pantograph-catenary system of the Chengdu-Chongqing passenger special railway is adopted as the analysis object. The absolute nodal coordinate formulation (ANCF) is employed to build the catenary model, of which the numerical accuracy is validated via the comparison with the field measurement data collected from an inspection vehicle operating at $378 \mathrm{~km} / \mathrm{h}$. A special spatial grid is defined for the pantographcatenary system to generate the stochastic wind field based on the empirical spectrum. According to the quasi-steady theory, the wind load acting on the catenary is derived. Computational fluid dynamics (CFD) is employed to calculate the lift and drag forces acting on each component of the 
pantograph, which are used to derive the equivalent aerodynamic force that can be applied in the lumped-mass model. The simulation results indicate that the pantograph-catenary system of Chengdu-Chongqing passenger special railway has an acceptable performance with a crosswind speed of $20 \mathrm{~m} / \mathrm{s}$. But when the crosswind increases up to $30 \mathrm{~m} / \mathrm{s}$, some contact force statistics exceed the safety threshold with a turbulence intensity of more than $17 \%$. Through the analysis of the operational safety, it is found that the contact wire always works within the safety range of the pantograph head with a crosswind speed of $30 \mathrm{~m} / \mathrm{s}$. But some safety issues can be seen from the maximum uplift of the pantograph head with a turbulence intensity of more than $21 \%$.

Keywords: Electric Railway; Catenary; Pantograph; Current Collection Quality; Crosswind; Stochastic Analysis

\section{Introduction}

Due to the complexity of the modern high-speed railway system, many independent relationships exist among the vehicle [1], the infrastructure [2], the overhead system [3] and the environmental disturbance [4], which interact, depend upon and restrict each other. A significant example is the pantograph-catenary system, responsible for transmitting electric power to the electric train [5]. As shown in Figure 1, the catenary is a tensioned cable structure constructed along the railroad. The electric current is transferred from the catenary to the pantograph through a sliding contact between the contact wire and the pantograph head. The current collection quality of the electric train is determined by the interaction performance between the catenary and pantograph.

As the most vulnerable part of the traction power system [6], the catenary is a long-span structure with high flexibility, which is very susceptible to crosswind. A substantial wind load can 
aggravate the vibration of the pantograph-catenary system, which may increase the contact force fluctuation [7], the risk of contact loss and the occurrence of arcing [8]. These issues affect the stable transmission of the electricity [9], which definitely deteriorates the current collection quality and aggravates the wear and ablation of the contact surface [10], reducing service life. It is necessary to evaluate the interaction performance of the pantograph-catenary subjected to the crosswind load, especially in the design phase.

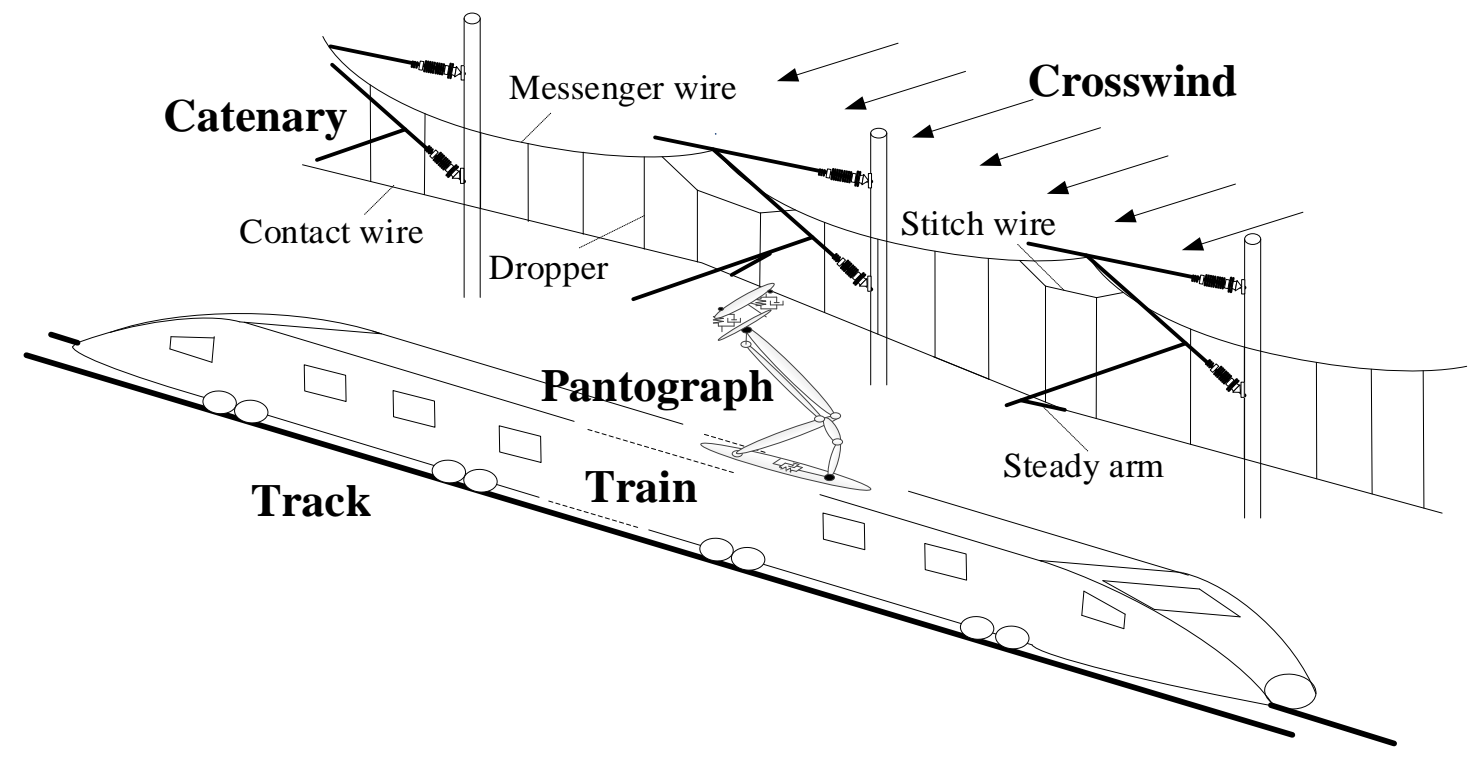

Figure 1. Railway pantograph-catenary system with crosswind

The mathematical model of pantograph-catenary has been a primary tool to evaluate the contact force, which is the main indicator to reflect the contact quality between the contact wire and the pantograph head. The modelling technique of pantograph-catenary experiences a significant advancement in the last decades, as summarised in [9]. The catenary is normally modelled by the finite element method or finite difference method [10], which can effectively describe the wave propagation [11], the geometrical nonlinearity [12] and the dropper slackness [13]. The pantograph is normally modelled by a lumped-mass model which can reflect the first two or three critical modes 
$[14,15]$. Some multibody dynamics models of pantograph are also developed to reproduce a realistic geometry [16-18]. Some realistic disturbances, such as the wear [19], the irregularity [20, 21], the geometrical deviation [14] and the vehicle perturbations [22], are properly modelled and included in the numerical model to evaluate the contact forces.

The wind load, which presents one of the main environmental disturbances to the long-span structure and moving vehicle [23], also attracts the interest of some scholars from the railway engineering community. The galloping of a catenary reported in $[24,25]$ is a rare phenomenon caused by aerodynamic instability. Once it happens, the catenary vibrates with huge amplitude, and the pantograph cannot run through the contact wire. The buffeting is the most common windinduced vibration for the catenary in daily operation, which has a direct impact on the contact force. In [26], the fluctuating wind field along the railway catenary is constructed using empirical spectrums. The wind-induced vibration and its effect on the contact forces are analysed. But the wind load on the pantograph is not considered in this work. In [27], the pantograph aerodynamics is considered to evaluate the contact force. But the stochastics of the wind load is not taken into account. In [28], the Pseudo-Excitation Method is used to evaluate the dispersion of the catenary response subjected to a crosswind. However, the geometrical nonlinearity and dropper slackness cannot be involved in a response spectrum analysis method.

These shortfalls in previous research are addressed in this paper to evaluate the effect of crosswind on the pantograph-catenary interaction performance. The analysis object of this paper is the Chengdu-Chongqing passenger special railway in China high-speed network, as shown in Figure 2. The top design speed for this railway is $380 \mathrm{~km} / \mathrm{h}$. In this work, the current collection quality under crosswind is evaluated based on a pantograph-catenary model validated at $378 \mathrm{~km} / \mathrm{h}$ through 
an experimental test. The aerodynamic coefficients of the catenary are obtained through a wind tunnel test. A CFD model of the pantograph is built to analyse the pantograph aerodynamics with a crosswind. The stochastic wind field is constructed along the catenary, and the current collection quality is evaluated through a stochastic analysis.

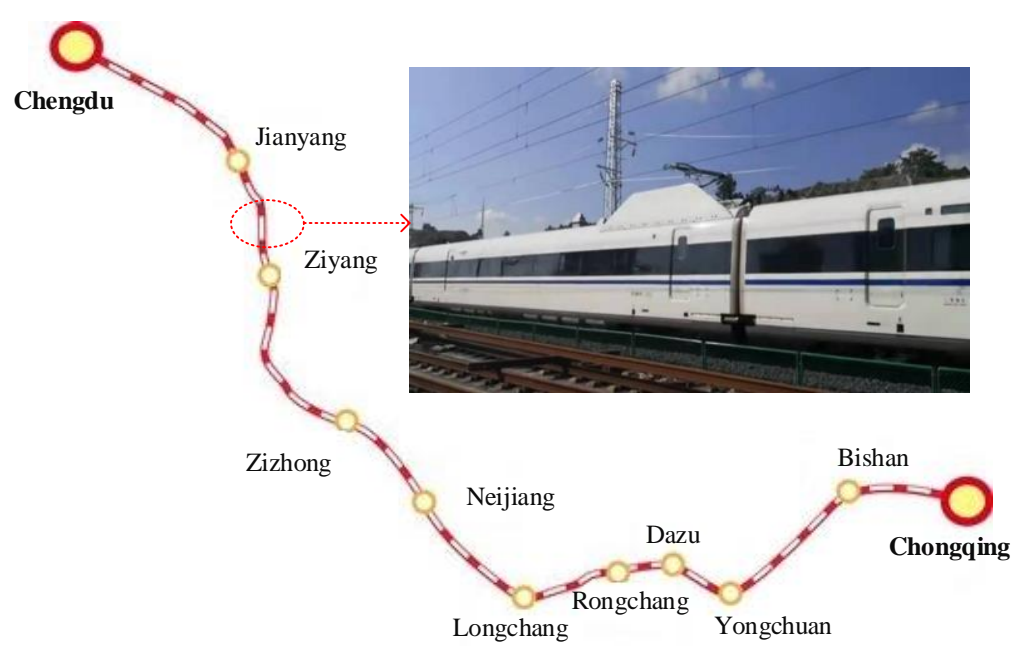

Figure 2. Chengdu-Chongqing passenger special railway

\section{Pantograph-Catenary Formulations}

In order to govern the large deformation of the catenary under the impact from both the pantograph and wind load, the ANCF beam is adopted to model the contact wire, messenger wire and stitch wire [29]. The catenary is modelled based on the design parameters in Chengyu high-speed railway. The model is validated by comparison with the field test data at $378 \mathrm{~km} / \mathrm{h}$.

\subsection{Catenary model}




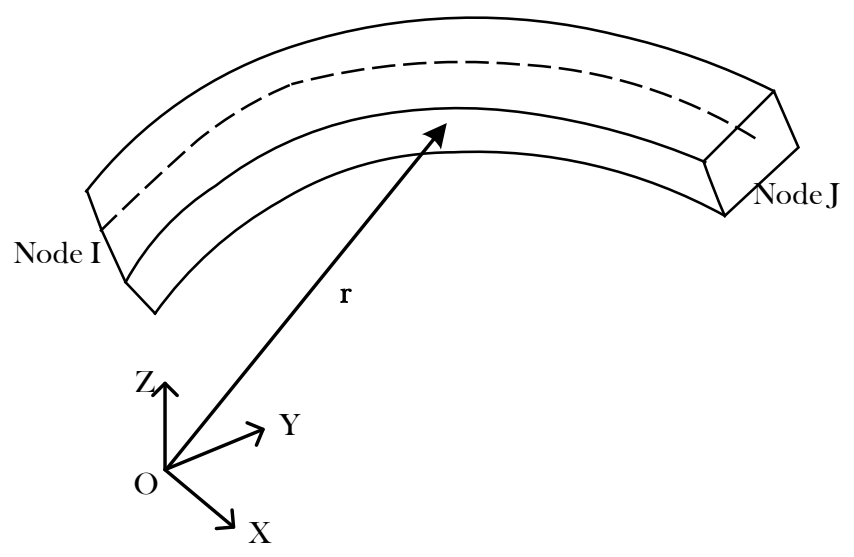

Figure 3. ANCF beam element

The ANCF is a nonlinear finite element approach that can effectively describe the flexibility of the catenary [30]. In this work, the ANCF beam element is used to model the tensioned wires (including contact wire, messenger wire and stitch wire). The ANCF cable element is adopted to model the dropper wire. The steady arm is modelled by the truss element. The claws and clamps on the wire are assumed as lumped masses. For an ANCF beam element [31], as shown in Figure 3, the nodal degree of freedom (DOF) vector that contains the displacements and the gradients are defined as:

$$
\mathbf{e}=\left[\begin{array}{llllllllllll}
x_{i} & y_{i} & z_{i} & \frac{\partial x_{i}}{\partial \chi} & \frac{\partial y_{i}}{\partial \chi} & \frac{\partial z_{i}}{\partial \chi} & x_{j} & y_{j} & z_{j} & \frac{\partial x_{j}}{\partial \chi} & \frac{\partial y_{j}}{\partial \chi} & \frac{\partial z_{j}}{\partial \chi}
\end{array}\right]^{\mathrm{T}}
$$

in which $\chi$ is the local coordinate in the undeformed configuration ranging from 0 to the unstrained length $L_{0}$. The position vector in the deformed configuration $\mathbf{r}$ is interpolated using the shape function matrix $\mathbf{N}$ as

$$
\mathbf{r}=\mathrm{Ne}
$$

in which $\mathbf{N}$ can be defined as follows: 


$$
\begin{aligned}
& \mathbf{N}=\left[\begin{array}{llllllllllll}
S_{1} & & & S_{2} & & & S_{3} & & & S_{4} & & \\
& S_{1} & & & S_{2} & & & S_{3} & & & S_{4} & \\
& & S_{1} & & & S_{2} & & & S_{3} & & & S_{4}
\end{array}\right] \\
& S_{1}(\xi)=1-3 \xi^{2}+2 \xi^{3} \\
& S_{2}(\xi)=l_{0}\left(\xi+\xi^{3}-2 \xi^{2}\right) \\
& S_{3}(\xi)=3 \xi^{2}-2 \xi^{3} \\
& S_{4}(\xi)=l_{0}\left(\xi^{3}-\xi^{2}\right)
\end{aligned}
$$

The strain energy obtained from the contribution of axial and bending deformation is expressed by

$$
U=\frac{1}{2} \int_{0}^{L_{0}}\left(E A \varepsilon_{l}^{2}+E I \kappa^{2}\right) d \chi
$$

in which $E$ is Young's modulus, $A$ is the section area, $I$ is the moment inertial of the wire, $\varepsilon_{l}$ is the longitudinal strain and $\kappa$ is the curvature. Differentiating both sides of Eq. (4), the element stiffness matrix $\mathbf{K}_{\mathrm{e}}$ can be derived as follows:

$$
\mathbf{Q}=\left(\frac{\partial U}{\partial \mathbf{e}}\right)^{T}=\mathbf{K}_{\mathrm{e}} \mathbf{e}
$$

In the shape-finding procedure, the tangent stiffness matrix is used to calculate the incremental nodal DOF vector $\Delta \mathbf{e}$ and the incremental unstrained length $\Delta L_{0}$. The corresponding tangent stiffness matrices $\mathbf{K}_{\mathrm{T}}$ and $\mathbf{K}_{\mathrm{L}}$ can be obtained as follows:

$$
\Delta \mathbf{F}=\frac{\partial \mathbf{Q}}{\partial \mathbf{e}} \Delta \mathbf{e}+\frac{\partial \mathbf{Q}}{\partial L_{0}} \Delta L_{0}=\mathbf{K}_{\mathrm{T}} \Delta \mathbf{e}+\mathbf{K}_{\mathrm{L}} \Delta L_{0}
$$

Similarly, the tangent stiffness matrices of the ANCF cable element can also be derived. It should be noted that the axial stiffness changes to zero when the dropper works in slackness. The shape-finding procedure has been given in [21] with details.

With the help of a finite element procedure, the global mass matrix $\mathbf{M}_{\mathrm{C}}^{\mathrm{G}}$ and the global stiffness matrix $\mathbf{K}_{\mathrm{C}}^{\mathrm{G}}$ are assembled by the element matrix of each component as follows:

$$
\begin{aligned}
& \mathbf{M}_{\mathrm{C}}^{\mathrm{G}}=\sum_{n_{\mathrm{cw}}} \mathbf{M}_{\mathrm{cw}, n}^{\mathrm{e}}+\sum_{n_{\mathrm{mw}}} \mathbf{M}_{\mathrm{mw}, n}^{\mathrm{e}}+\sum_{n_{\mathrm{dr}}} \mathbf{M}_{\mathrm{dr}, n}^{\mathrm{e}}+\sum_{n_{\mathrm{cs}}} \mathbf{M}_{\mathrm{sa}, n}^{\mathrm{e}}+\sum_{n_{\mathrm{cl}}} \mathbf{M}_{\mathrm{cl}, n}^{\mathrm{e}} \\
& \mathbf{K}_{\mathrm{C}}^{\mathrm{G}}=\sum_{n_{\mathrm{cw}}} \mathbf{K}_{\mathrm{cw}, n}^{\mathrm{e}}+\sum_{n_{\mathrm{mw}}} \mathbf{K}_{\mathrm{mw}, n}^{\mathrm{e}}+\sum_{n_{\mathrm{dr}}} \mathbf{K}_{\mathrm{dr}, n}^{\mathrm{e}}+\sum_{n_{\mathrm{cs}}} \mathbf{K}_{\mathrm{sa}, n}^{\mathrm{e}}+\sum_{n_{\mathrm{ms}}} \mathbf{K}_{\mathrm{ms}, n}^{\mathrm{e}}
\end{aligned}
$$


in which, $\mathbf{M}_{\mathrm{cw}, n}^{\mathrm{e}}, \mathbf{M}_{\mathrm{mw}, n}^{\mathrm{e}}, \mathbf{M}_{\mathrm{dr}, n}^{\mathrm{e}}, \mathbf{M}_{\mathrm{sa}, n}^{\mathrm{e}}$ and $\mathbf{M}_{\mathrm{cl}, n}^{\mathrm{e}}$ represent the element mass matrix of contact wire, messenger wire, dropper, steady arm and claw, respectively. $\mathbf{K}_{\mathrm{cw}, n}^{\mathrm{e}}, \mathbf{K}_{\mathrm{mw}, n}^{\mathrm{e}}, \mathbf{K}_{\mathrm{dr}, n}^{\mathrm{e}}, \mathbf{K}_{\mathrm{sa}, n}^{\mathrm{e}}$ and $\mathbf{K}_{\mathrm{ms}, n}^{\mathrm{e}}$ denote the corresponding stiffness matrices. Employing a Rayleigh damping matrix $\mathbf{C}_{\mathrm{C}}^{\mathrm{G}}$ , the equation of motion for the catenary can be written by

$$
\mathbf{M}_{\mathrm{C}}^{\mathrm{G}} \ddot{\mathbf{U}}_{\mathrm{C}}(t)+\mathbf{C}_{\mathrm{C}}^{\mathrm{G}} \dot{\mathbf{U}}_{\mathrm{C}}(t)+\mathbf{K}_{\mathrm{C}}^{\mathrm{G}}(t) \mathbf{U}_{\mathrm{C}}(t)=\mathbf{F}_{\mathrm{C}}^{\mathrm{G}}(t)
$$

in which, $\mathbf{U}_{\mathrm{C}}(t)$ and $\mathbf{F}_{\mathrm{C}}^{\mathrm{G}}(t)$ are the vectors of DOF and external force at the time instant $t$.

\subsection{Modelling of the pantograph}

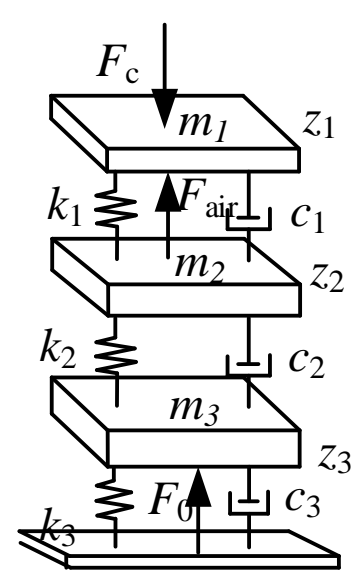

Figure 4. Lumped-mass model of pantograph

A widely-used lumped-mass model of the pantograph, as shown in Figure 4, is adopted in the numerical simulation. The lumped parameters are obtained from the experimental test on a realistic pantograph, which can efficiently describe the three critical vertical modes. The equation of motion can be written as

$$
\left\{\begin{array}{l}
m_{1} \ddot{z}_{1}+c_{1}\left(\dot{z}_{1}-\dot{z}_{2}\right)+k_{1}\left(z_{1}-z_{2}\right)=-F_{\mathrm{c}}+F_{\text {air }} \\
m_{2} \ddot{z}_{2}+c_{1}\left(\dot{z}_{2}-\dot{z}_{1}\right)+c_{2}\left(\dot{z}_{2}-\dot{z}_{3}\right)+k_{1}\left(z_{2}-z_{1}\right)+k_{2}\left(z_{2}-z_{3}\right)=0 \\
m_{3} \ddot{z}_{3}+c_{2}\left(\dot{z}_{3}-\dot{z}_{2}\right)+c_{3} \dot{z}_{3}+k_{2}\left(z_{3}-z_{2}\right)+k_{3} z_{3}=F_{0}
\end{array}\right.
$$


in which $m_{1}, m_{2}$ and $m_{3}$ are the equivalent mass of the pantograph head, upper arm and lower arm, respectively. $k_{1}, k_{2}$ and $k_{3}$ are the corresponding equivalent stiffness. $c_{1}, c_{2}$ and $c_{3}$ are the corresponding equivalent damping. $F_{0}$ is the uplift force. $F_{\mathrm{c}}$ is the contact force. $F_{\text {air }}$ is the equivalent aerodynamic force, which is the contribution of aerodynamic forces acting on each pantograph component to the contact force. The derivation of $F_{\text {air }}$ is presented in Section 4.

\subsection{Modelling of contact}

The contact between the pantograph collector and contact wire is described by the penalty method as follows.

$$
f_{\mathrm{c}}= \begin{cases}k_{\mathrm{c}}\left(y_{\mathrm{p}}-y_{\mathrm{c}}\right) & y_{\mathrm{p}} \geq y_{\mathrm{c}} \\ 0 & y_{\mathrm{p}}<y_{\mathrm{c}}\end{cases}
$$

Using the above equation, the equation of motion for the pantograph-catenary system can be obtained as

$$
\mathbf{M}^{\mathrm{G}} \ddot{\mathbf{U}}(t)+\mathbf{C}^{\mathrm{G}} \dot{\mathbf{U}}(t)+\mathbf{K}^{\mathrm{G}}(t) \mathbf{U}(t)=\mathbf{F}^{\mathrm{G}}(t)
$$

in which $\mathbf{M}^{\mathrm{G}}, \mathbf{C}^{\mathrm{G}}$ and $\mathbf{K}^{\mathrm{G}}(t)$ are the mass, damping and stiffness matrices for the whole pantograph-catenary system, respectively. $\mathbf{F}^{\mathrm{G}}(t)$ is the external force vector. A Newmark integration scheme is adopted to solve Eq. (16). The stiffness matrix $\mathbf{K}^{\mathrm{G}}(t)$ is updated each time step to adequately describe the nonlinearity from the wire deformation and the dropper slackness.

\subsection{Validation with Experimental Test}

To validate the numerical model presented above and analyse the pantograph-catenary interaction performance at super-higher speed, an instrumented pantograph (see Figure 4) is mounted on an inspection vehicle (see Figure 5), which regularly runs on China high-speed network. According to 
En 50317 [32], the instrumented pantograph is equipped with four accelerometers on its pantograph collector, collecting the inertial part of the contact force. Two spring sensors are placed under the pantograph head to measure the inner forces between the collector and the framework. The contact force can be seen as the sum of the inner forces, inertial forces and the aerodynamic force as follows:

$$
f_{\mathrm{c}}=\sum_{i=1}^{n_{\mathrm{f}}} f_{\text {inner }, i}+\frac{m_{\mathrm{eq}}}{n_{\mathrm{a}}} \sum_{i=1}^{n_{\mathrm{a}}} a_{\text {head }, i}+f_{\text {aero }}
$$

in which $f_{\text {inner }, i}$ is the inner force. $n_{\mathrm{f}}$ is the number of spring sensors. $m_{\mathrm{eq}}$ is the equivalent mass of the pantograph head. $n_{\mathrm{a}}$ is the number of accelerometers on the pantograph head. $a_{\text {head }, i}$ is the acceleration measured by each accelerometer. $f_{\text {aero }}$ is the aerodynamic correction part, which has been determined in a wind tunnel test.

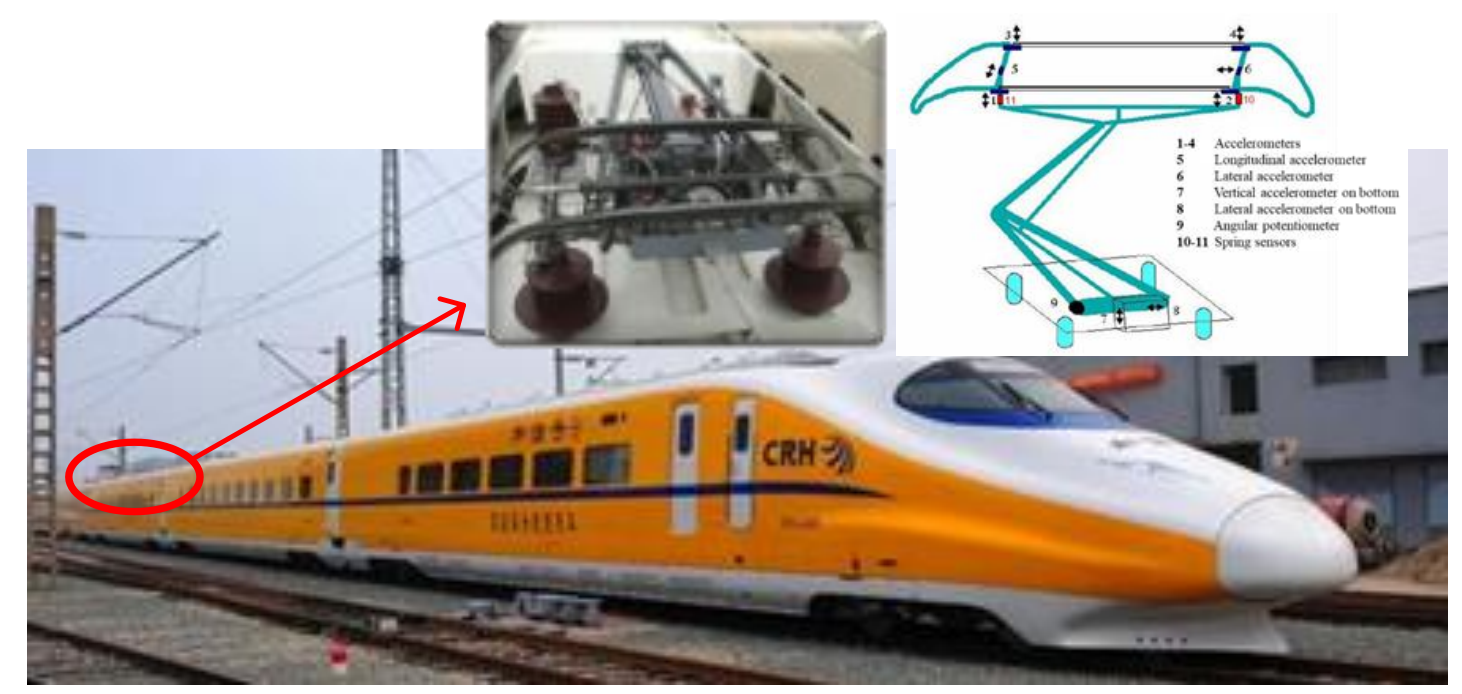

Figure 5. High-speed inspection vehicle with an Instrumented pantograph

The measurement contact force is collected from a super-high-speed field test in Chengdu-

Chongqing high-speed line. The running speed of the inspection vehicle reaches $378 \mathrm{~km} / \mathrm{h}$ in this test to explore the ultimate service performance at the maximum design speed. The two tensile sections (from $83.093 \mathrm{~km}$ to $85.981 \mathrm{~km}$ ) are taken as the analysis object. According to the design data, the catenary model with two tensile sections is constructed using the aforementioned method. 
The initial configuration of the catenary is presented in Figure 6. Then the dynamic simulation is performed with a TSG-19-type pantograph. The measurement and simulation contact forces are presented in Figure. 7. It is seen that the fluctuation range of the simulation contact force shows a good agreement with the measurement contact force. According to En 50317 [32], the measurement data has an up to $10 \%$ inevitable error due to the limitation of the measurement equipment. Therefore the contact force waveform cannot be directly used for comparison. Some statistics of the contact force and uplift specified in En 50318 [33] are typically used to validate the numerical model. The comparison of these statistics is presented in Table 3. It is seen that the most important indicator, contact force standard deviation evaluated by the present model, only has a $4.17 \%$ error against the measurement data, which is much smaller than the threshold of $20 \%$. The uplifts of the pantograph head and the support are almost identical to the measurement values. Even though the actual maximum and minimum contact forces are not included in the validation in En 50318, the most significant difference of these values against the measurement data is still smaller than $20 \%$. Through the comparison, it can be demonstrated that the present model has good performance to evaluate the comprehensive and local behaviours of the pantograph-catenary interaction.

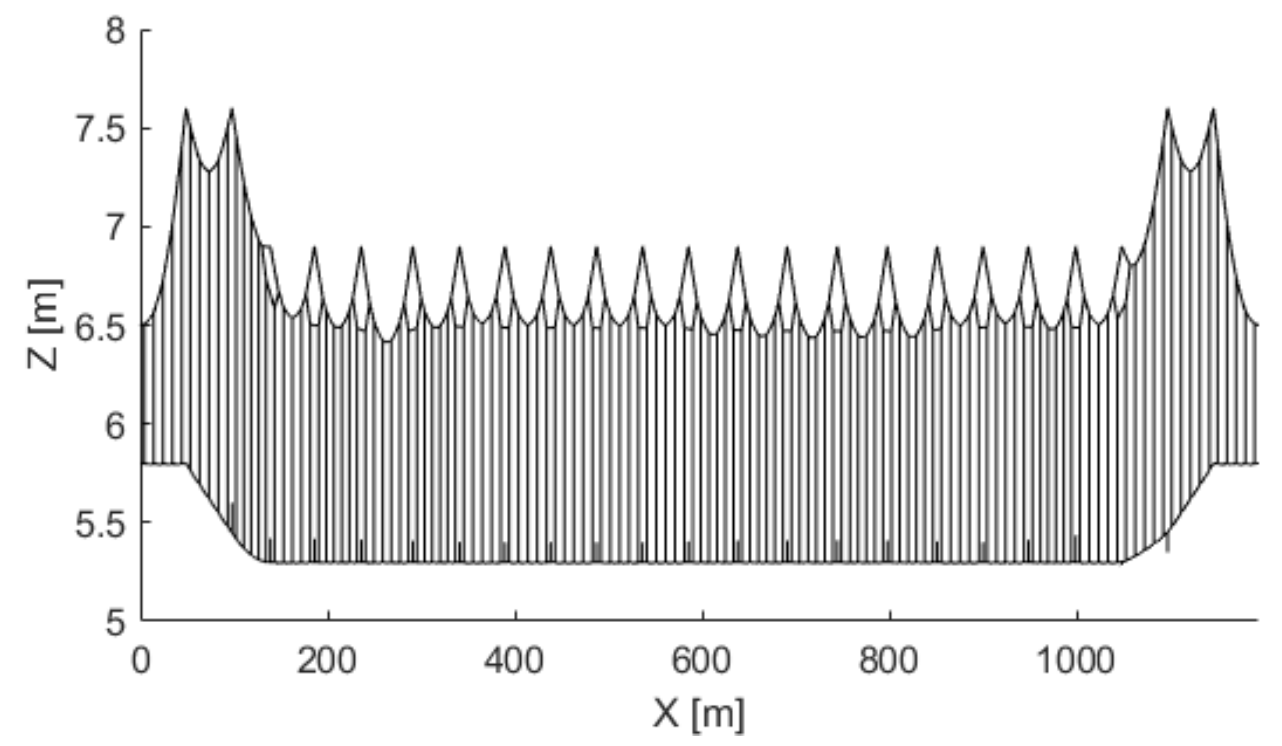


Figure 6. Initial configuration of Chengdu-Chongqing high-speed catenary

Table 1. Comparison of critical indicators between simulation and measurement

\begin{tabular}{ccccc}
\hline & Measurement & Simulation & Error & Threshold \\
\hline Speed [km/h] & 378 & 378 & $/$ & $/$ \\
Mean [N] & 188.22 & 188.81 & $0.59 \mathrm{~N}$ & $\pm 2.5 \mathrm{~N}$ \\
Standard deviation [N] & 32.81 & 34.76 & $5.94 \%$ & $\pm 20 \%$ \\
Statistical maximum [N] & 286.65 & 293.09 & $2.25 \%$ & $/$ \\
Statistical minimum [N] & 89.79 & 84.53 & $5.86 \%$ & $/$ \\
Range of head vibration & $68 \mathrm{~mm}$ & $68.3 \mathrm{~mm}$ & $0.3 \mathrm{~mm}$ & $\pm 20 \mathrm{~mm}$ \\
Support uplift & $90 \mathrm{~mm}$ & 87.2 & $-2.8 \mathrm{~mm}$ & $-10 \mathrm{~mm} ;+20 \mathrm{~mm}$ \\
Actual maximum [N] & 308 & 271.97 & $11.7 \%$ & $/$ \\
Actual minimum [N] & $85 \mathrm{~N}$ & 90.71 & $6.72 \%$ & $/$ \\
\hline
\end{tabular}

\section{Derivation of Aerodynamic Forces Acting on Pantograph-Catenary}

In this section, the aerodynamic forces on the pantograph caused by the crosswind are derived based on the pantograph geometry and CFD simulation. The aerodynamic forces on the catenary are derived based on the Quasi-steady theory and spatial coordinate transformation.

\subsection{Derivation of Aerodynamic Forces on Catenary}

Figure 7 (a) presents a catenary system subjected to a crosswind. The aerodynamic forces acting on the contact wire can be derived according to the following procedure. The aerodynamic forces acting on other components can be obtained with a similar approach. The natural wind can be seen as the summation of the even wind $U$ and the fluctuating winds, which can be seen as the along-wind component $u$, crosswind component $v$ and vertical-wind component $w$. 
(a) Global reference system for catenary

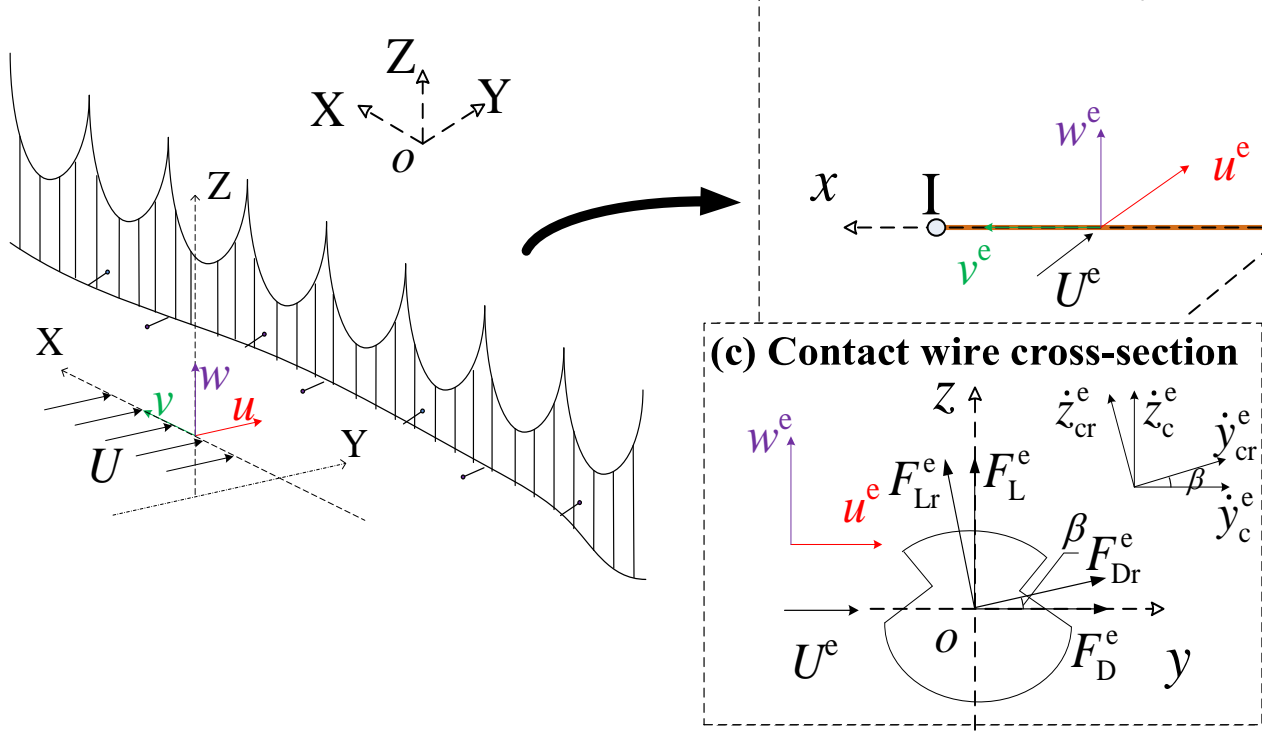

Figure 7. Derivation of aerodynamic forces acting on the contact wire: (a) Global reference

system; (b) Local reference system for each element; (c) Contact wire cross-section

As the contact wire is not perpendicular to the even wind direction, the aerodynamic forces have to be derived in the local reference system. For each element, the even wind $U^{\mathrm{e}}$ and fluctuating wind components $u^{\mathrm{e}}, v^{\mathrm{e}}$ and $w^{\mathrm{e}}$ in the element local reference system can be obtained by

$$
\left[\begin{array}{c}
v^{\mathrm{e}} \\
u^{\mathrm{e}} \\
w^{\mathrm{e}}
\end{array}\right]=\mathbf{T}(\mathbf{e})\left[\begin{array}{l}
v \\
u \\
w
\end{array}\right],\left[\begin{array}{c}
V^{\mathrm{e}} \\
U^{\mathrm{e}} \\
W^{\mathrm{e}}
\end{array}\right]=\mathbf{T}(\mathbf{e})\left[\begin{array}{c}
0 \\
U \\
0
\end{array}\right]
$$

in which $V^{\mathrm{e}}$ and $W^{\mathrm{e}}$ are the longitudinal and vertical components of the even wind in the element local reference system. $\mathbf{T}(\mathbf{e})$ is the spatial transformation matrix. Considering a crosswind, $W^{\mathrm{e}}$ is always equal to zero. The longitudinal components $V^{\mathrm{e}}$ and $v^{\mathrm{e}}$ can be neglected as they do not have a direct contribution to the wind-induced vibration. Figure 7 (c) shows a contact wire cross-section subjected to $U^{\mathrm{e}}, u^{\mathrm{e}}$ and $w^{\mathrm{e}}$. The drag $F_{\mathrm{D}}^{\mathrm{e}}$ and lift $F_{\mathrm{L}}^{\mathrm{e}}$ are the aerodynamic forces acting on the contact wire in the 'y-o-z' reference system. Following the fluid- 
induced vibration theory [34], the dynamic wind angle $b$ induced by the movement of the contact wire can be expressed by

$$
\beta=\arctan \left(\frac{w^{\mathrm{e}}-\dot{z}_{\mathrm{cr}}^{\mathrm{e}}}{U^{\mathrm{e}}+u^{\mathrm{e}}-\dot{y}_{\mathrm{cr}}^{\mathrm{e}}}\right)
$$

in which $\dot{z}_{\mathrm{cr}}^{\mathrm{e}}$ and $\dot{y}_{\mathrm{cr}}^{\mathrm{e}}$ are the vertical and lateral velocities of the contact wire in the reference system defined by the dynamic wind angle $b . \dot{z}_{\text {cr }}^{e}$ and $\dot{y}_{\text {cr }}^{e}$ can be obtained through a simple coordinate transformation of the vertical and lateral velocities $\dot{z}_{\mathrm{c}}^{\mathrm{e}}$ and $\dot{y}_{\mathrm{c}}^{\mathrm{e}}$ in the 'y-o-z' reference system as follows:

$$
\left\{\begin{array}{l}
\dot{y}_{\mathrm{cr}}^{\mathrm{e}}=\dot{y}_{\mathrm{c}}^{\mathrm{e}} \cos \beta+\dot{z}_{\mathrm{c}}^{\mathrm{e}} \sin \beta \\
\dot{z}_{\mathrm{cr}}^{\mathrm{e}}=\dot{z}_{\mathrm{c}}^{\mathrm{e}} \cos \beta-\dot{y}_{\mathrm{c}}^{\mathrm{e}} \sin \beta
\end{array}\right.
$$

The lift $F_{\mathrm{Lr}}^{\mathrm{e}}$ and drag $F_{\mathrm{Dr}}^{\mathrm{e}}$ in the reference system defined by the dynamic wind angle $b$ can be expressed by

$$
\left\{\begin{array}{l}
F_{\mathrm{Lr}}^{\mathrm{e}}=\frac{1}{2} \rho_{\text {air }} U_{\mathrm{r}}^{\mathrm{e}} L_{\mathrm{e}} D C_{\mathrm{L}}(\beta) \\
F_{\mathrm{Dr}}^{\mathrm{e}}=\frac{1}{2} \rho_{\text {air }} U_{\mathrm{r}}^{\mathrm{e}} L_{\mathrm{e}} D C_{\mathrm{D}}(\beta)
\end{array}\right.
$$

in which $\rho_{\text {air }}$ is the air density. $D$ is the diameter of the contact line cross-section. $C_{\mathrm{L}}(\beta)$ and $C_{\mathrm{D}}(\beta)$ are the lift and drag coefficients at the angle of attack $b . U_{\mathrm{r}}^{\mathrm{e}}$ is the effective wind velocity, which can be expressed by

$$
U_{\mathrm{r}}^{\mathrm{e}}=\sqrt{\left(w^{\mathrm{e}}-\dot{z}_{\mathrm{cr}}^{\mathrm{e}}\right)^{2}+\left(U^{\mathrm{e}}+u^{\mathrm{e}}-\dot{y}_{\mathrm{cr}}^{\mathrm{e}}\right)^{2}}
$$

According to the geometrical relationship, the drag $F_{\mathrm{D}}^{\mathrm{e}}$ and lift $F_{\mathrm{L}}^{\mathrm{e}}$ can be obtained as follows:

$$
\left\{\begin{array}{l}
F_{\mathrm{D}}^{\mathrm{e}}=F_{\mathrm{Dr}}^{\mathrm{e}} \cos (\beta)-F_{\mathrm{Lr}}^{\mathrm{e}} \sin (\beta) \\
F_{\mathrm{L}}^{\mathrm{e}}=F_{\mathrm{Dr}}^{\mathrm{e}} \sin (\beta)+F_{\mathrm{Lr}}^{\mathrm{e}} \cos (\beta)
\end{array}\right.
$$

Transferring $F_{\mathrm{D}}^{\mathrm{e}}$ and $F_{\mathrm{L}}^{\mathrm{e}}$ the global reference system yields the aerodynamic forces that can be directly applied in the finite element model. 
It is seen that the fluctuating components $u, v, w$ and the aerodynamic coefficients $C_{\mathrm{D}}$ and $C_{\mathrm{L}}$ should be obtained to determine the aerodynamic forces used in the numerical simulation. In this work, the wind tunnel test is conducted to measure the aerodynamic coefficients of a realistic contact wire subjected to a crosswind. As shown in Figure 8, a contact wire section is built with a scale ratio of 5:1. The wind tunnel test is conducted in the Fluid Mechanics Laboratory at the Department of Energy and Process Engineering, NTNU Gløshaugen. The measurement results of $C_{\mathrm{D}}$ and $C_{\mathrm{L}}$ are presented in Figure 9. Third-order polynomials are utilised to fit the curves of the measurement parameters, which are used in the numerical simulation to update the aerodynamic coefficients in each time step. The cross-sections for other wires (including the messenger wire, dropper and steady arm) are assumed to be circular. Therefore, the lift coefficient can be neglected. The drag coefficient $C_{\mathrm{D}}$ with different Reynolds numbers can be found in [35].

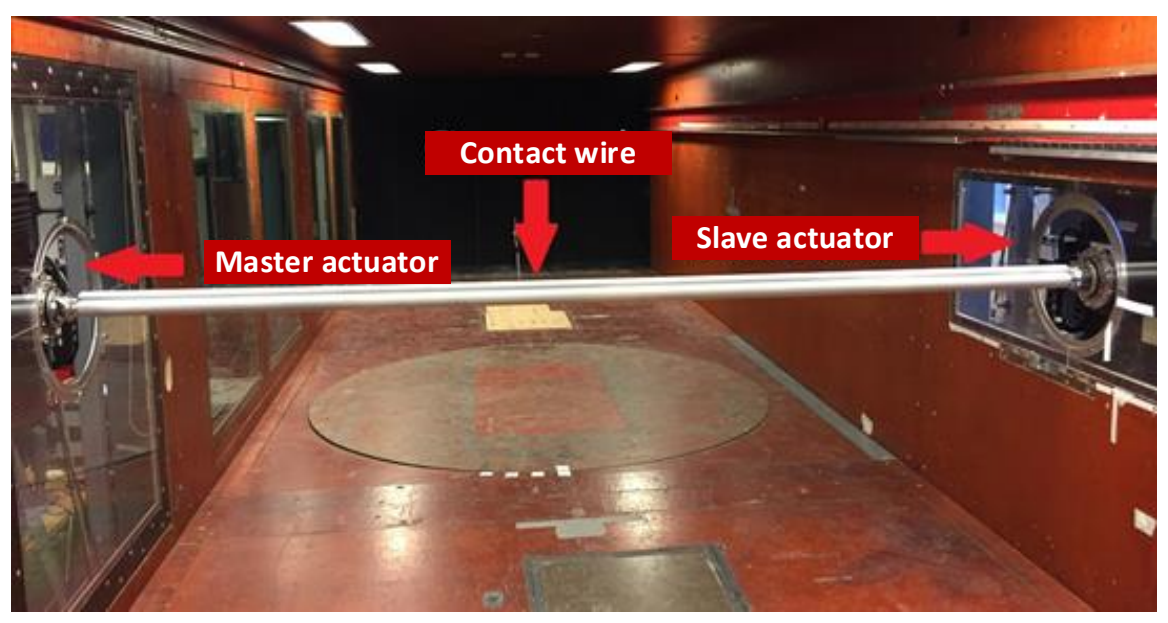

Figure 8. Wind tunnel test for the contact wire 


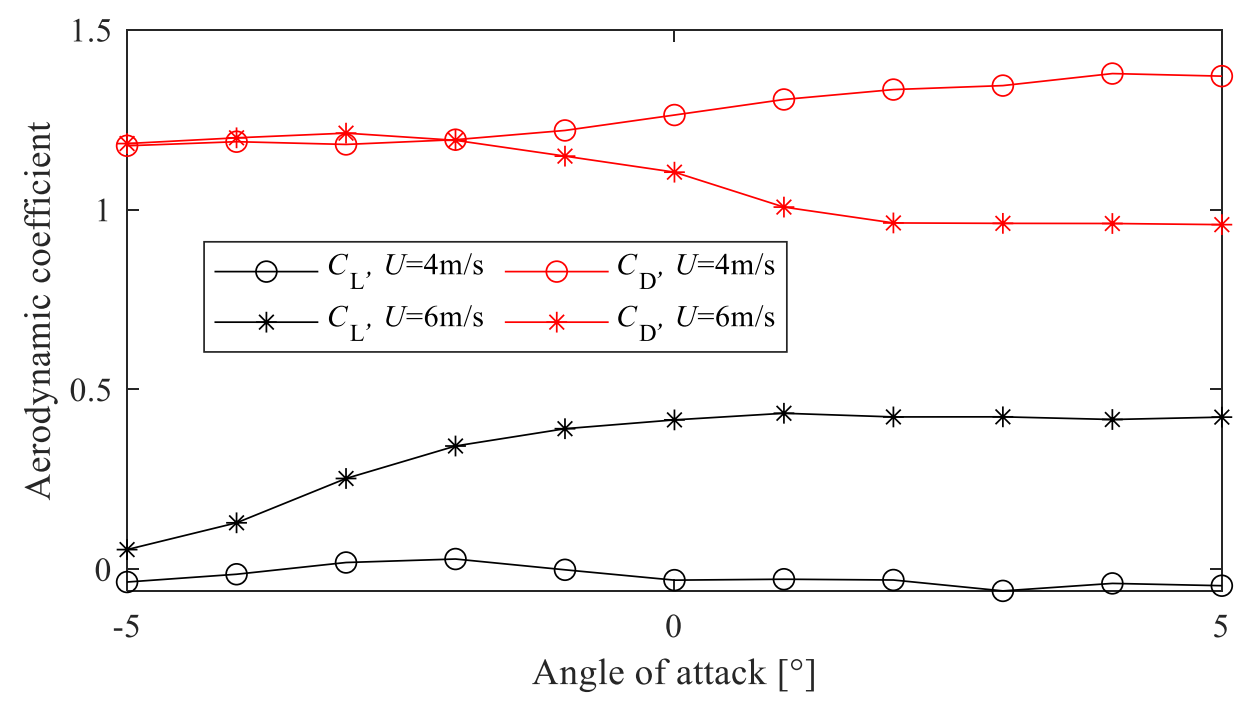

Figure 9. Measurement results of $C_{\mathrm{D}}$ and $C_{\mathrm{L}}$ for the contact wire

\subsection{Derivation of Aerodynamic Forces on Pantograph}

The pantograph uplift force is taken as the summation of the static contact force and the aerodynamic force. The contribution of the aerodynamic forces to the contact force can be derived with the help of Figure 10. Three main parts (namely the pantograph head, upper arm and lower arm) are kept in the derivation. The lift and drag forces acting on the pantograph head, upper arm and lower arm are represented by $F_{\mathrm{L}}^{\mathrm{ph}}, F_{\mathrm{D}}^{\mathrm{ph}}, F_{\mathrm{L}}^{\mathrm{ua}}, F_{\mathrm{D}}^{\mathrm{ua}}, F_{\mathrm{L}}^{\text {la }}, F_{\mathrm{D}}^{\text {la }}$ respectively. According to the pantograph geometry, their contribution to the contact force can be expressed by

$$
F_{\text {air }}=\left[\begin{array}{llllll}
\frac{\eta_{1}}{\kappa} & 1 & \frac{\eta_{2}}{\kappa} & \frac{\eta_{3}}{\kappa} & \frac{\eta_{4}}{v} & \frac{\eta_{5}}{v}
\end{array}\right]\left[\begin{array}{c}
F_{\mathrm{D}}^{\mathrm{ph}} \\
F_{\mathrm{L}}^{\mathrm{ph}} \\
F_{\mathrm{D}}^{\text {ua }} \\
F_{\mathrm{L}}^{\text {ua }} \\
F_{\mathrm{D}}^{\text {la }} \\
F_{\mathrm{L}}^{\text {la }}
\end{array}\right]
$$

in which 


$$
\begin{aligned}
& \eta_{1}=l_{\mathrm{a}} \sin \alpha \sin (\gamma-\theta)-l_{3} \sin \theta \sin (\beta+\gamma) \\
& \eta_{2}=l_{2} \sin \alpha \sin (\gamma-\theta)-l_{3} \sin \theta \sin (\beta+\gamma) \\
& \eta_{3}=l_{2} \cos \alpha \sin (\gamma-\theta)+l_{3} \cos \theta \sin (\beta+\gamma) \\
& \eta_{4}=-l_{3} l_{5} \sin \theta \sin (\beta+\gamma) \\
& \eta_{5}=-l_{3} l_{5} \cos \theta \sin (\beta+\gamma) \\
& \kappa=l_{\mathrm{a}} \cos \alpha \sin (\gamma-\theta)+l_{3} \cos \theta \sin (\beta+\gamma) \\
& \left.v=l_{\mathrm{b}} l_{\mathrm{a}} \cos \alpha \sin (\gamma-\theta)+l_{3} \cos \theta \sin (\beta+\gamma)\right] \\
& l_{\mathrm{a}}=l_{1}+l_{2} \\
& l_{\mathrm{b}}=l_{1}+l_{2}
\end{aligned}
$$

where $\alpha, \beta, \gamma$ and $\theta$ denote the rotation angles of different arms in the pantograph, as shown in Figure 10. According to the geometrical relationships between the pantograph arms, the rotation angles $\alpha, \beta$ and $\gamma$ can be expressed as follows when $\theta$ is determined.

$$
\begin{aligned}
& \gamma=\pi-\arctan \frac{l_{\mathrm{e}}}{l_{\mathrm{f}}}-\arccos \frac{\psi_{1}^{2}+\psi_{2}^{2}-l_{\mathrm{b}}^{2}}{2 \psi_{1} \psi_{2}}-\arccos \frac{\psi_{1}^{2}+l_{\mathrm{c}}^{2}-l_{3}^{2}}{2 \psi_{1} l_{\mathrm{c}}} \\
& \beta=\arccos \frac{l_{3}^{2}+l_{\mathrm{c}}^{2}-\psi_{1}^{2}}{2 l_{3} l_{\mathrm{c}}}-\gamma \\
& \alpha=\arccos \frac{l_{3}^{2}+l_{\mathrm{a}}^{2}-\psi_{1}^{2}}{2 l_{\mathrm{a}} l_{3}}+\beta-\pi
\end{aligned}
$$

in which,

$$
\begin{aligned}
& \psi_{1}=\sqrt{l_{\mathrm{b}}^{2}+\psi_{2}^{2}-2 l_{\mathrm{b}} \psi_{2} \cos \left(\theta+\arctan \frac{l_{\mathrm{e}}}{l_{\mathrm{f}}}\right)} \\
& \psi_{2}=\sqrt{l_{\mathrm{e}}^{2}+l_{\mathrm{f}}^{2}}
\end{aligned}
$$

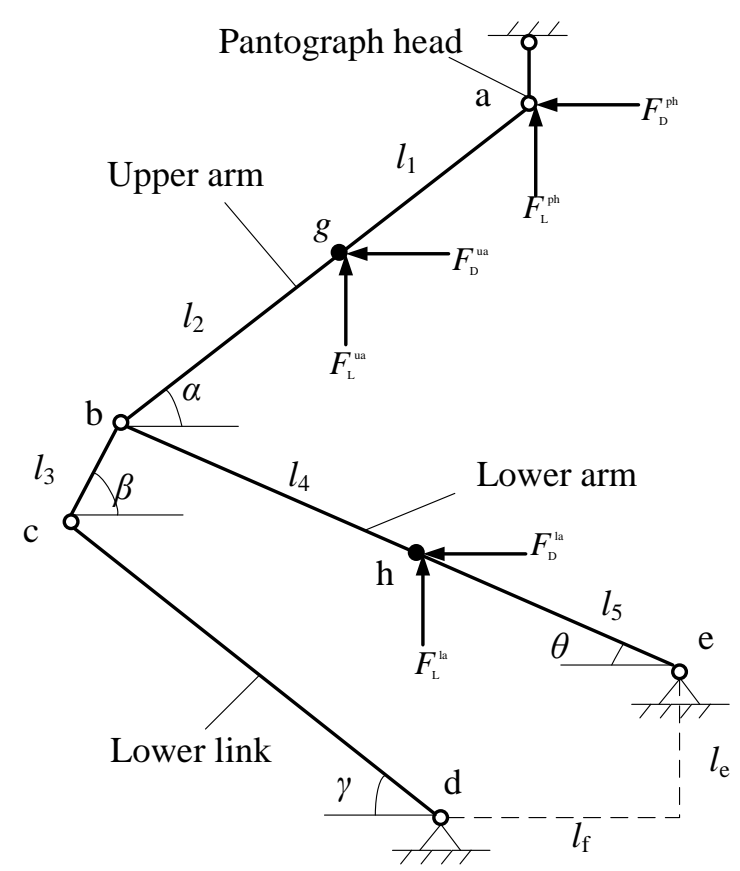

Figure 10. Derivation of aerodynamic forces in a pantograph 
The aerodynamic forces $F_{\mathrm{L}}^{\mathrm{ph}}, F_{\mathrm{D}}^{\mathrm{ph}}, F_{\mathrm{L}}^{\text {ua }}, F_{\mathrm{D}}^{\mathrm{ua}}, F_{\mathrm{L}}^{\text {la }}, F_{\mathrm{D}}^{\text {la }}$ are calculated by the CFD in Ansys Fluent. A CFD pantograph model is constructed as shown in Figure 11 according to the realistic geometry of an SSS400+ pantograph. Neglecting joint details, only the pantograph head, upper and lower arms are modelled, which can be seen in the local view shown in Figure 11 (b). Figure 11 (a) shows that the entire flow area is $1000 \mathrm{~m}$ long, $850 \mathrm{~m}$ wide, and $100 \mathrm{~m}$ high, and the total number of mesh is about 10 million. Due to the complex geometry of the pantograph, the unstructured grid is used to discrete the region near the pantograph, and the minimum mesh length is $0.001 \mathrm{~m}$. The side boundary is defined as velocity-inlet to simulate the crosswind effect. The train speed defined in the simulation is $378 \mathrm{~km} / \mathrm{h}$, and the crosswind speed is defined from 0 to $40 \mathrm{~m} / \mathrm{s}$ with an interval of $5 \mathrm{~m} / \mathrm{s}$. The resulting lift and drag forces, $F_{\mathrm{L}}^{\mathrm{ph}}, F_{\mathrm{D}}^{\mathrm{ph}}, F_{\mathrm{L}}^{\mathrm{ua}}, F_{\mathrm{D}}^{\mathrm{ua}}, F_{\mathrm{L}}^{\text {la }}, \quad F_{\mathrm{D}}^{\mathrm{la}}$ acting on the pantograph head, upper arm and lower arm are presented in Figure 12. It is seen that both the lift and drag undergo a continuous increase with the crosswind speed. Using Eq. (19), the equivalent aerodynamic force $F_{\text {air }}$ is calculated and presented in Figure 13. Two-order polynomials are employed to fit the curves of the calculated results. The explicit formulas are given as follows:

$$
F_{\text {air }}=0.0199 W^{2}+0.5759 W+131.9
$$

in which $W$ represents the crosswind speed. Eq. (23) is used in the simulation to update the aerodynamic force acting on the pantograph in each time step.

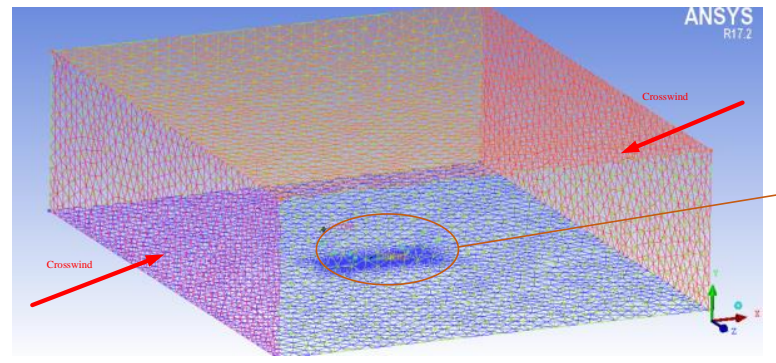

(a)

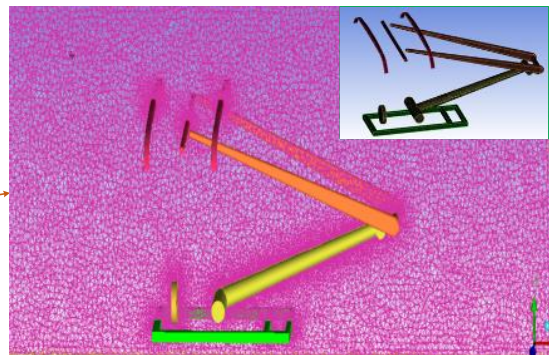

(b)

Figure 11. CFD model of pantograph: (a) global view; (b) local view 


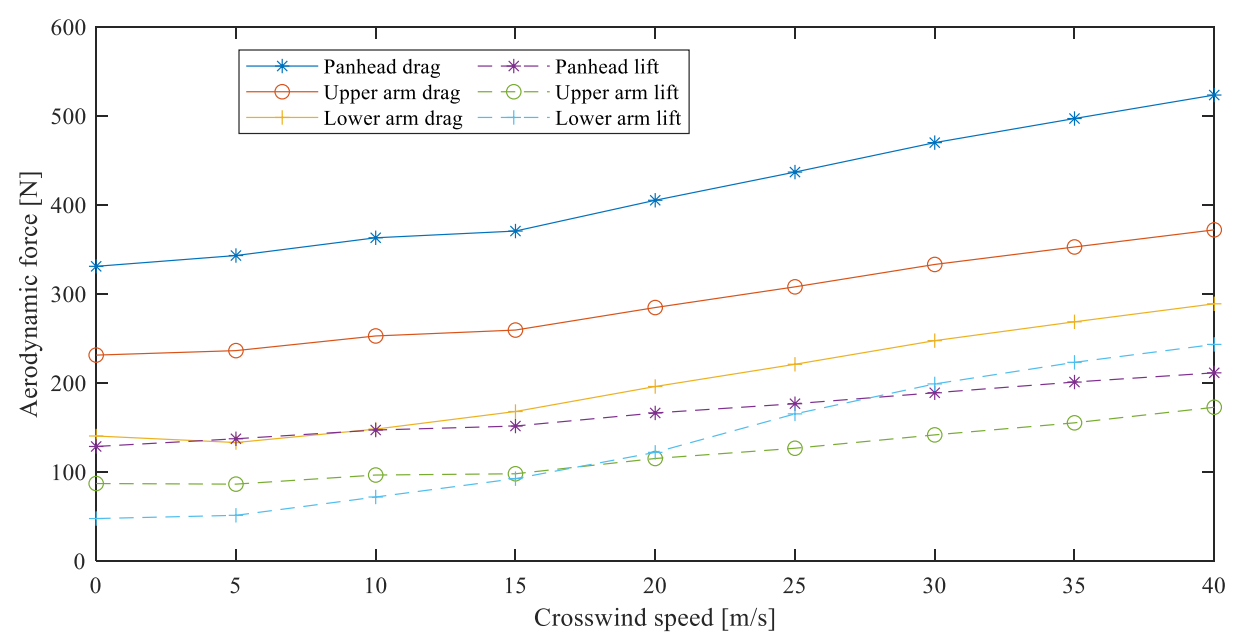

Figure 12. Lift and drag forces acting on the pantograph head, upper arm and lower arm

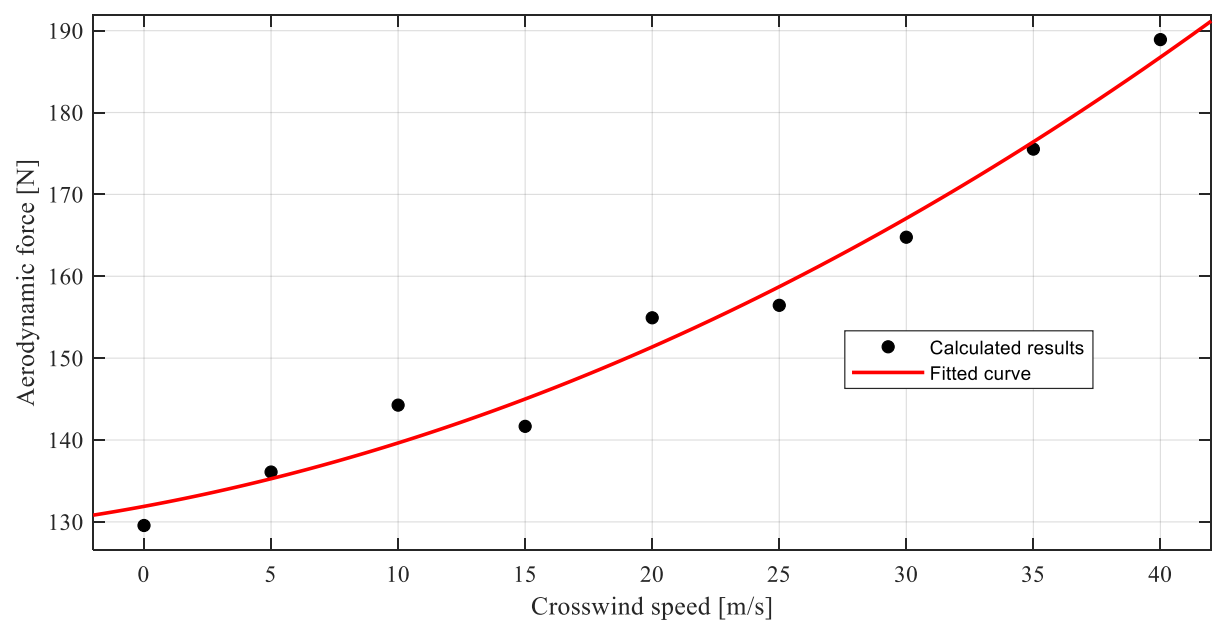

Figure 13. Equivalent aerodynamic force acting on the pantograph

\section{Wind Field Construction}

The stochastic wind field is constructed by inversing the empirical spectrum to time history. The Von Karman spectrums [36] in longitudinal, lateral and vertical directions are adopted here.

Considering the spatial correlation, the spectral matrix is generated as follows. Therefore, for two arbitrary spatial points $M$ and $P$, the cross-spectral density matrix for the wind components in the two points can be expressed by 


$$
\mathbf{S}_{\mathrm{v}}^{M, P}(\omega)=\left[\begin{array}{ccc}
\sqrt{S_{\mathrm{u}}^{M} S_{\mathrm{u}}^{P}} & 0 & \operatorname{coh}_{\mathrm{uv}}^{M, P} \sqrt{S_{\mathrm{u}}^{M} S_{\mathrm{v}}^{P}} \\
0 & \sqrt{S_{\mathrm{w}}^{M} S_{\mathrm{w}}^{P}} & 0 \\
\operatorname{coh}_{\mathrm{vu}}^{M, P} \sqrt{S_{\mathrm{v}}^{M} S_{\mathrm{u}}^{P}} & 0 & \sqrt{S_{\mathrm{v}}^{M} S_{\mathrm{v}}^{P}}
\end{array}\right]
$$

in which $\operatorname{coh}_{\varepsilon \eta}^{M, P}$ represents the correlation function between two points $M$ and $P$ in $\varepsilon$ and $\eta$ ( $\varepsilon, \eta=\mathrm{u}, \mathrm{w}, \mathrm{v})$ directions. It should be noted that the longitudinal and vertical wind components are not correlated. That is why the corresponding correlation function is zero. The power spectral density matrix for one point $M$ is

$$
\mathbf{S}_{\mathrm{v}}^{M}(\omega)=\left[\begin{array}{ccc}
S_{\mathrm{u}}^{M} & 0 & \operatorname{coh}_{\mathrm{uv}}^{M, M} \sqrt{S_{\mathrm{u}}^{M} S_{\mathrm{v}}^{M}} \\
0 & S_{\mathrm{w}}^{M} & 0 \\
\operatorname{coh}_{\mathrm{vu}}^{M, M} \sqrt{S_{\mathrm{v}}^{M} S_{\mathrm{u}}^{M}} & 0 & S_{\mathrm{v}}^{M}
\end{array}\right]
$$

A spatial grid is necessary to determine the global power spectral density matrix $\mathbf{S}_{\mathrm{v}}(\omega)$ by assembling Eqs. (24) and (25). For the analysed catenary shown in Figure 6, the spatial grid is depicted in Figure 14. It is seen that the spatial grid has four layers in the vertical direction. The top one is for the messenger wire and stitch wire. The second one is for dropper wires. The third one is for the contact wire, and the last one is for the pantograph.

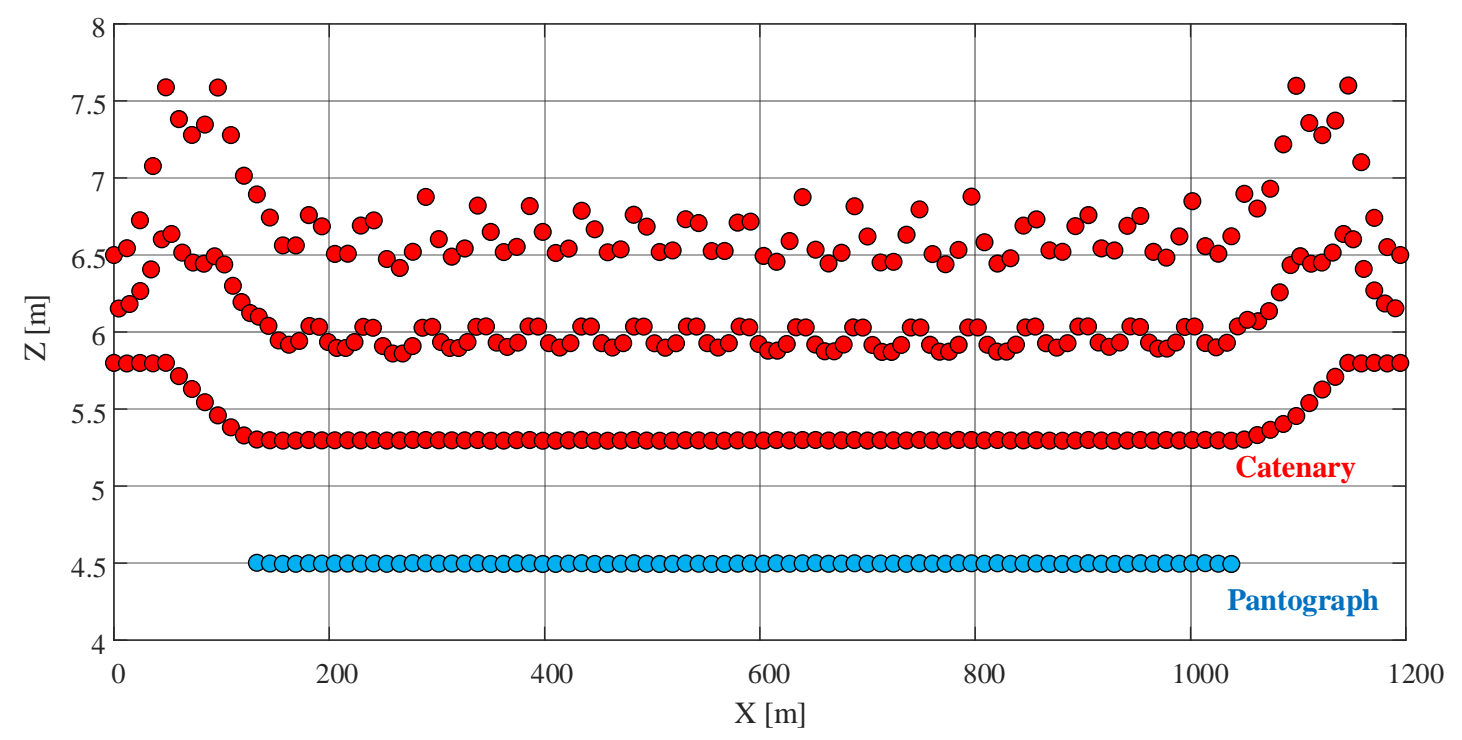

Figure 14. Spatial grid of wild field for pantograph-catenary 


\section{Performance Assessment with Crosswind}

In this section, the pantograph-catenary system's current collection quality and operation safety are evaluated under the crosswind with different turbulence intensities. The terrain categories primarily determine the turbulence intensity. For open terrains, the turbulence intensity usually is no more than $20 \%$. But for some complex terrains, big turbulence may be expected. In the simulations, the turbulence intensity changes from $9 \%$ to $27 \%$. The crosswind speeds of $20 \mathrm{~m} / \mathrm{s}$ and $30 \mathrm{~m} / \mathrm{s}$ are adopted in the assessment. According to the design specification [37], the current collection quality and the operation safety should be ensured in the serviceability limit state, in which the maximum wind speed is mostly $30 \mathrm{~m} / \mathrm{s}$. The train speed is set as $378 \mathrm{~km} / \mathrm{h}$, which is very close to the maximum design speed and has been validated against the measurement data in Table 1. The main indicators adopted in this assessment of current collection quality are the standard deviation, the statistical maximum and the statistical minimum of contact forces filtered within $0-20 \mathrm{~Hz}$ [38]. The maximum lateral deviation of contact point and maximum vertical uplift of pantograph head are analysed to evaluate the operational safety under crosswind.

\subsection{Preliminary analysis of Current Collection Quality}

The evaluated contact force statistics (namely the standard deviation, statistical maximum and statistical minimum) as a function of turbulence intensity with the crosswind speed of $20 \mathrm{~m} / \mathrm{s}$ and $30 \mathrm{~m} / \mathrm{s}$ are presented in Figure 15 (a) and (b). It is seen that the increase of the turbulence intensity causes a significant rise in the standard deviation and the statistical maximum contact force, but a sharp decrease of the statistical minimum contact force. At $30 \mathrm{~m} / \mathrm{s}$ wind speed, the statistical minimum contact force is below the safety threshold $0 \mathrm{~N}$ with a turbulence intensity of more than $18 \%$. The threshold for statistical maximum contact force is $350 \mathrm{~N}$ for the operating speed up to 350 
$\mathrm{km} / \mathrm{h}$. Currently, no technical specifications have been reported for $378 \mathrm{~km} / \mathrm{h}$ operating speed. A reasonable threshold $450 \mathrm{~N}$ is adopted (as an example) for the statistical maximum contact force to facilitate the assessment in this analysis. It is seen that all the resulting statistical maximum contact forces are within the safety threshold at $20 \mathrm{~m} / \mathrm{s}$ wind speed. However, at $30 \mathrm{~m} / \mathrm{s}$ wind speed, the statistical maximum contact force is out of the safety limit with more than $21 \%$ turbulence intensity.

The contact force time histories with the crosswind speed of $20 \mathrm{~m} / \mathrm{s}$ and $30 \mathrm{~m} / \mathrm{s}$ are presented in Figure 16 (a) and (b), respectively. At each wind speed, the contact force fluctuation exhibits a sharp increase with the increasing turbulence intensity. Some contact loss can be observed when the turbulence intensity increases up to $25 \%$.

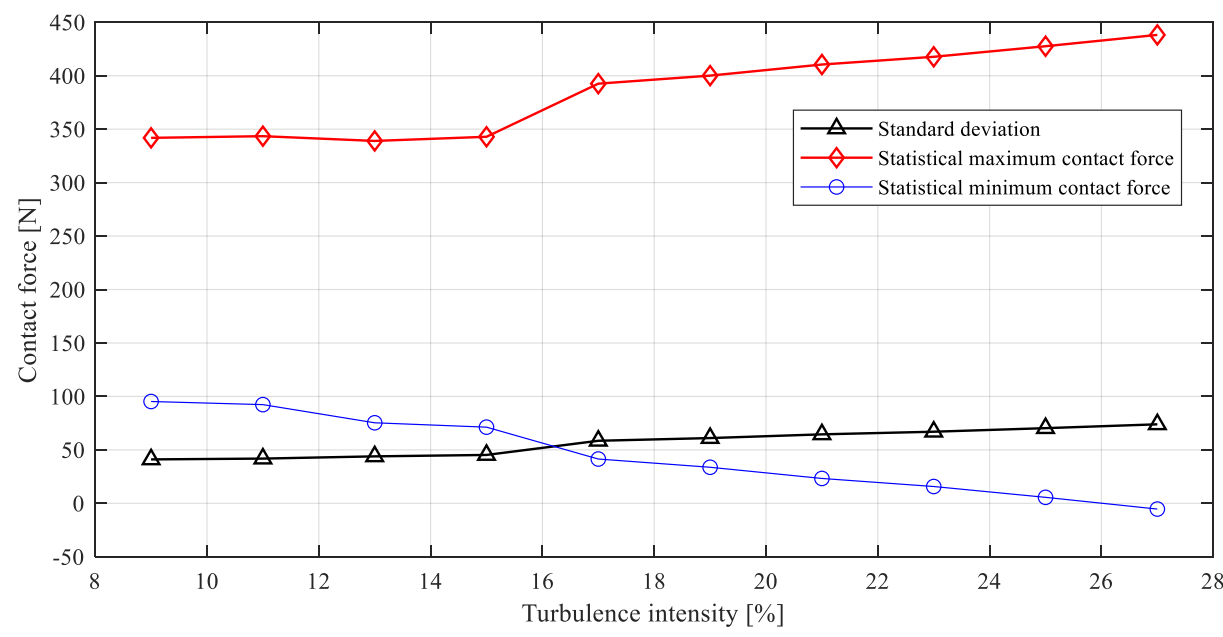

(a)

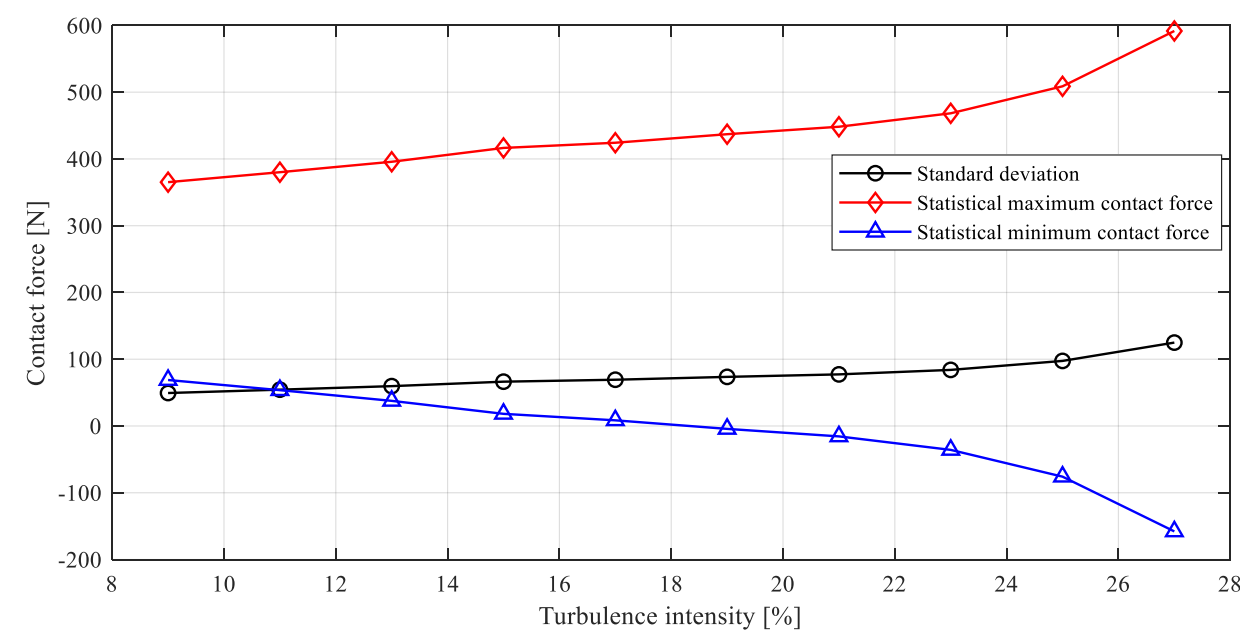


(b)

Figure 15. Contact force statistics with crosswind speed of (a) $20 \mathrm{~m} / \mathrm{s}$ and $30 \mathrm{~m} / \mathrm{s}$

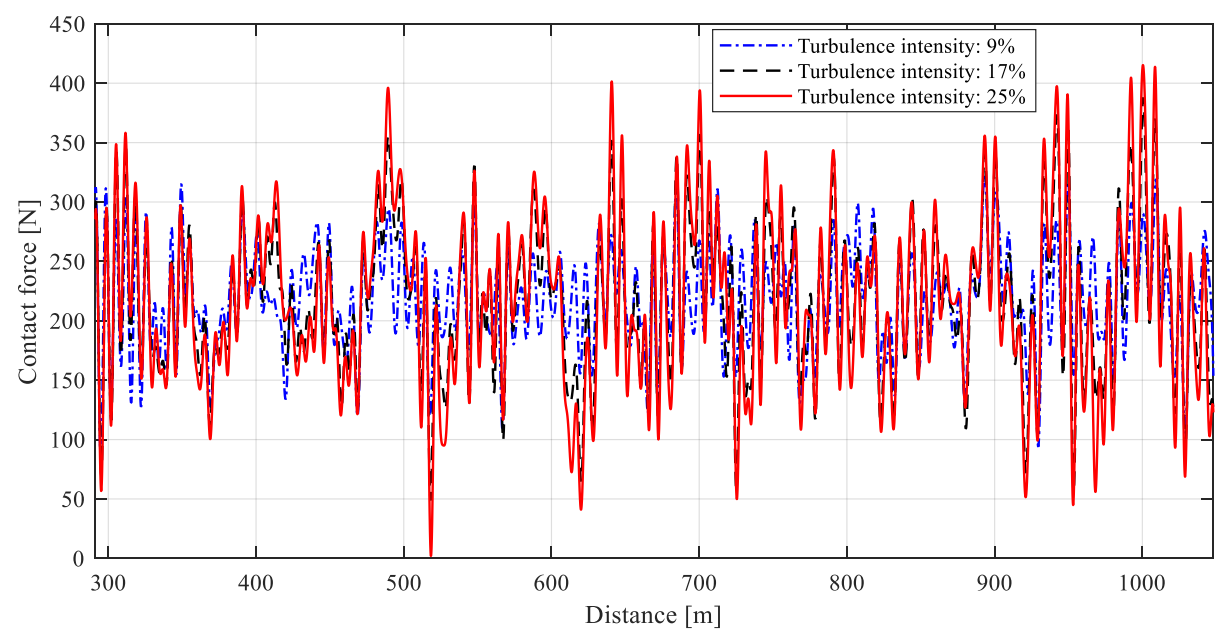

(a)

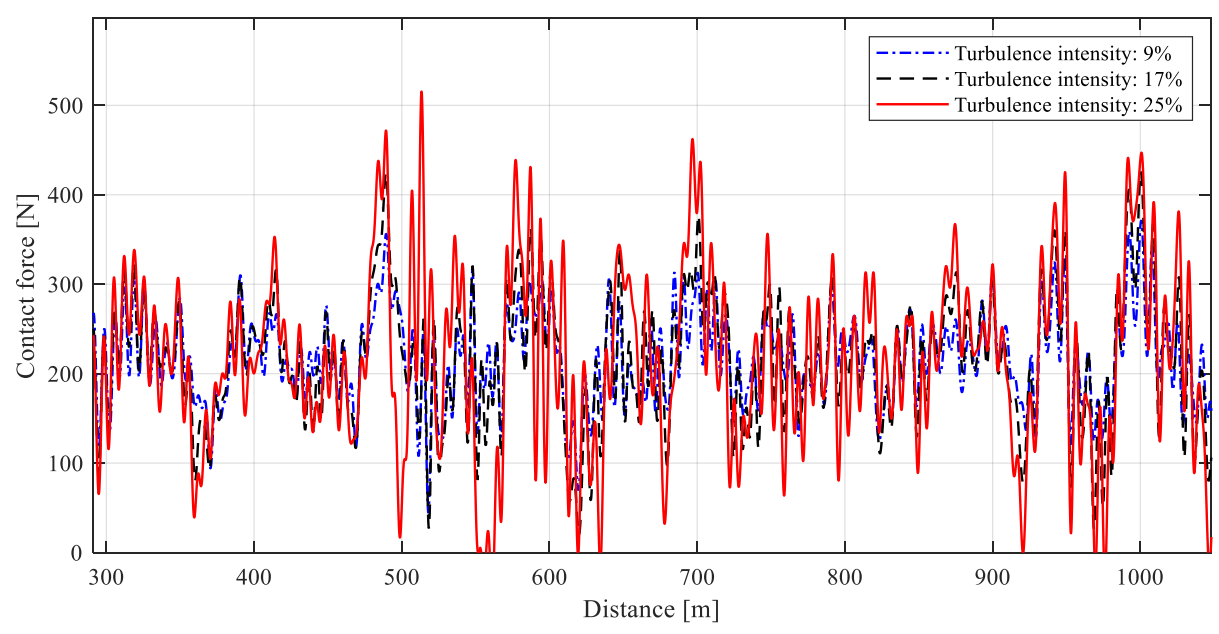

(b)

Figure 16. Contact force time history with crosswind speed of (a) $20 \mathrm{~m} / \mathrm{s}$ and $30 \mathrm{~m} / \mathrm{s}$

\subsection{Stochastic Analysis of Current Collection Quality}

Note that the above analysis in Section 5.1 only uses one case of fluctuating crosswind field with each wind speed and turbulence intensity. Due to the stochastic nature of wind load, different fluctuating wind speed time-histories following the same spectrum can be obtained, which definitely causes the dispersion of the pantograph-catenary interaction results. In this section, 200 fluctuating 
wind speed time histories are generated to perform a stochastic analysis. The boxplots of contact force standard deviation with the crosswind speed of $20 \mathrm{~m} / \mathrm{s}$ and $30 \mathrm{~m} / \mathrm{s}$ are presented in Figure 17 (a) and (b), respectively. It is seen that the fluctuating wind causes a significant dispersion of the resulting contact force standard deviation. The increase of the turbulence intensity also causes the increase of the dispersion. Figure 18 (a) and (b) show the boxplots of statistical maximum contact force with crosswind speeds of $20 \mathrm{~m} / \mathrm{s}$ and $30 \mathrm{~m} / \mathrm{s}$, respectively. It is seen that all the results evaluated at $20 \mathrm{~m} / \mathrm{s}$ crosswind speed are within the safety limit. However, at $30 \mathrm{~m} / \mathrm{s}$ crosswind speed, some results exceeding the safety limit can be observed with the intensity turbulence of $21 \%$ and 25\%. Figure 19 (a) and (b) show the boxplots of statistical minimum contact force with crosswind speed of $20 \mathrm{~m} / \mathrm{s}$ and $30 \mathrm{~m} / \mathrm{s}$, respectively. It is seen that all the statistical minimum contact forces are bigger than $0 \mathrm{~N}$ at $20 \mathrm{~m} / \mathrm{s}$ crosswind speed, while some negative results can be seen when the turbulence intensity is more than $17 \%$ at $30 \mathrm{~m} / \mathrm{s}$ crosswind speed.

From the boxplot analysis, it is seen that the pantograph-catenary has an acceptable performance at $20 \mathrm{~m} / \mathrm{s}$ crosswind speed. Some issues of current collection quality can be observed at $30 \mathrm{~m} / \mathrm{s}$, which is the serviceability limit state for most pantograph-catenary systems. A probabilistic analysis is performed here to quantify the possibility of exceeding the safety threshold. The probability density function (PDF) of the statistical maximum and minimum contact forces with a crosswind speed of $30 \mathrm{~m} / \mathrm{s}$ is presented in Figure 20 (a) and (b), respectively. It is seen that the statistical maximum contact force has a $0 \%, 2.65 \%, 47.53 \%$ and $89.85 \%$ possibility to exceed the safety threshold with the turbulence intensity of $13 \%, 17 \%, 21 \%$ and $25 \%$, respectively. The statistical minimum contact force has a $0 \%, 12.58 \%, 73.03 \%$ and $96.92 \%$ possibility to be negative with the turbulence intensity of $13 \%, 17 \%, 21 \%$ and $25 \%$, respectively. Thus, more attention should 
be paid to improve the wind-resistant capability when the railway crosses a complex terrain with a turbulence intensity of more than $17 \%$.

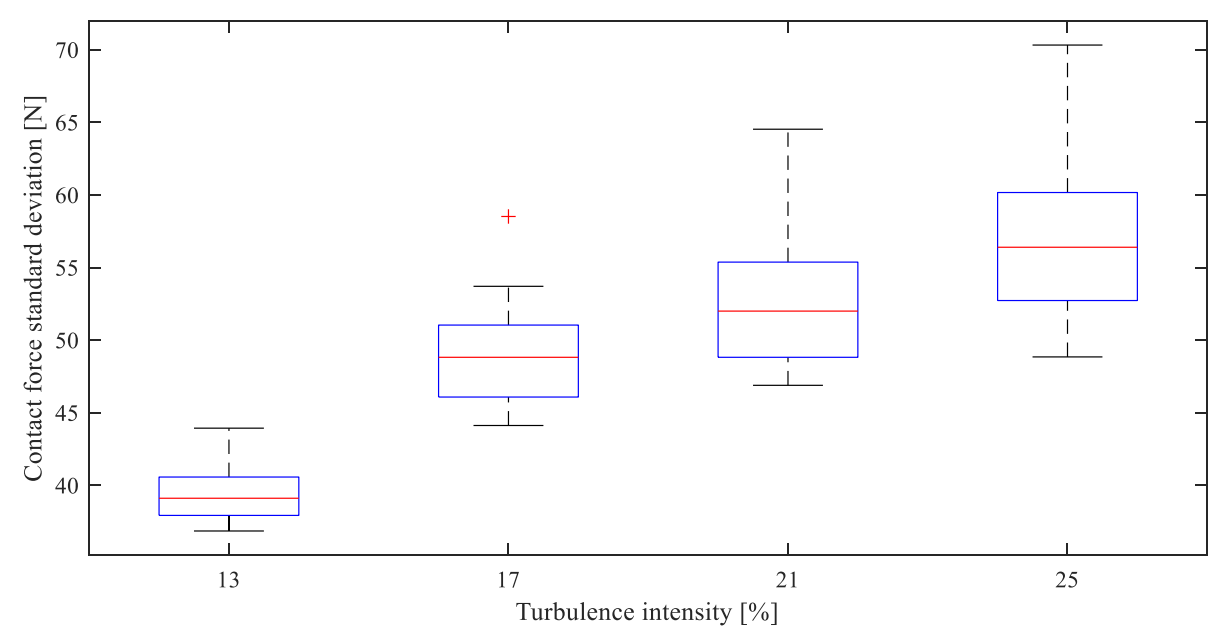

(a)

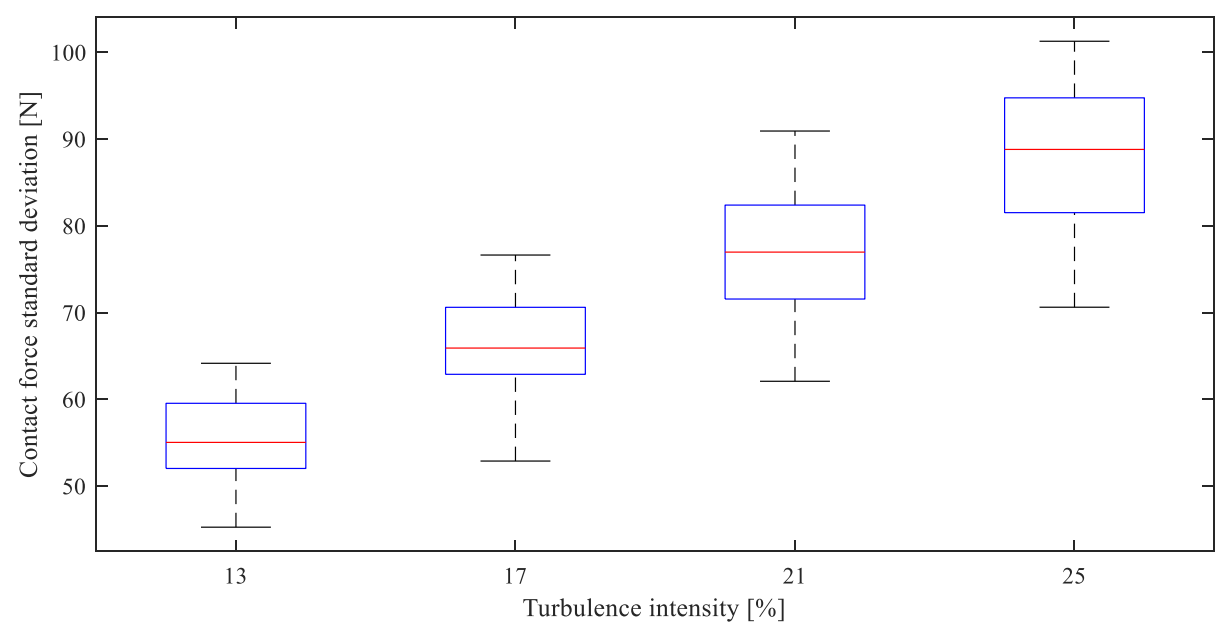

(b)

Figure 17. Boxplots of contact force standard deviation with crosswind speed of $20 \mathrm{~m} / \mathrm{s}$ and $30 \mathrm{~m}$ $/ \mathrm{s}$ 


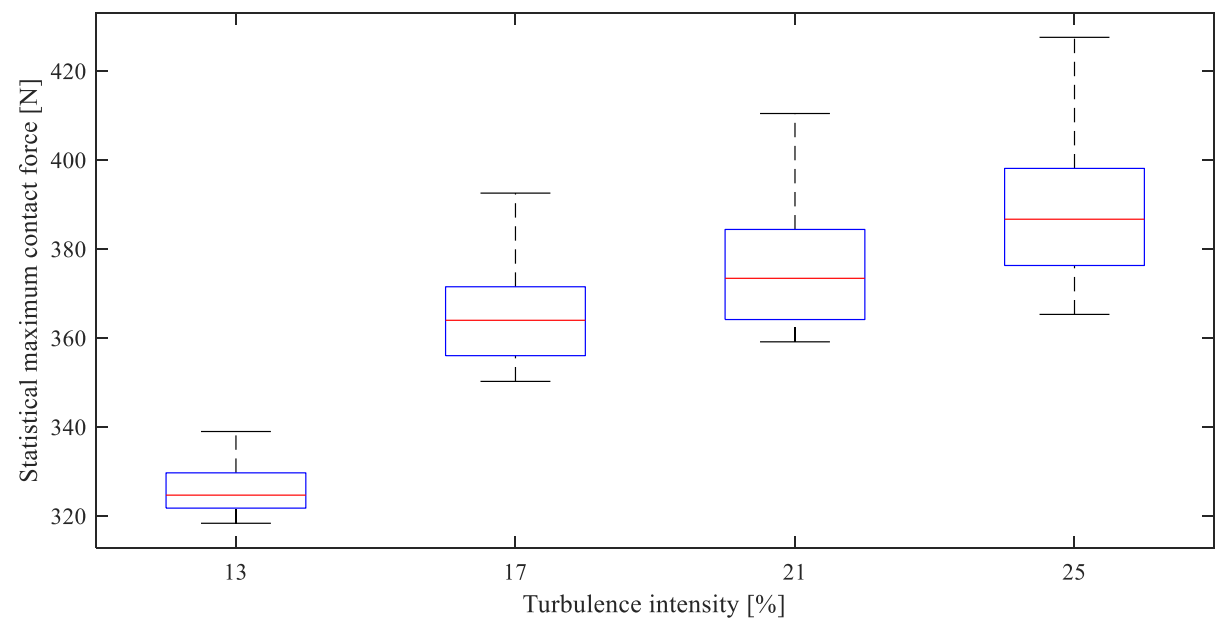

(a)

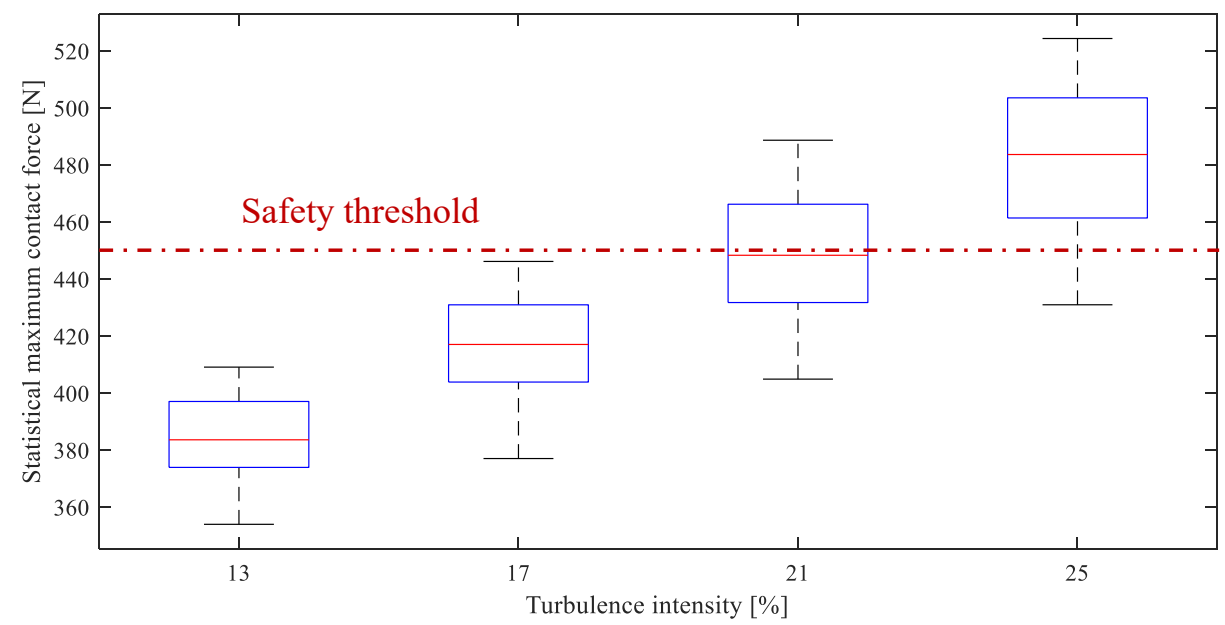

(b)

Figure 18. Boxplots of statistical maximum contact force with crosswind speed of (a) $20 \mathrm{~m} / \mathrm{s}$ and (b) $30 \mathrm{~m} / \mathrm{s}$ 


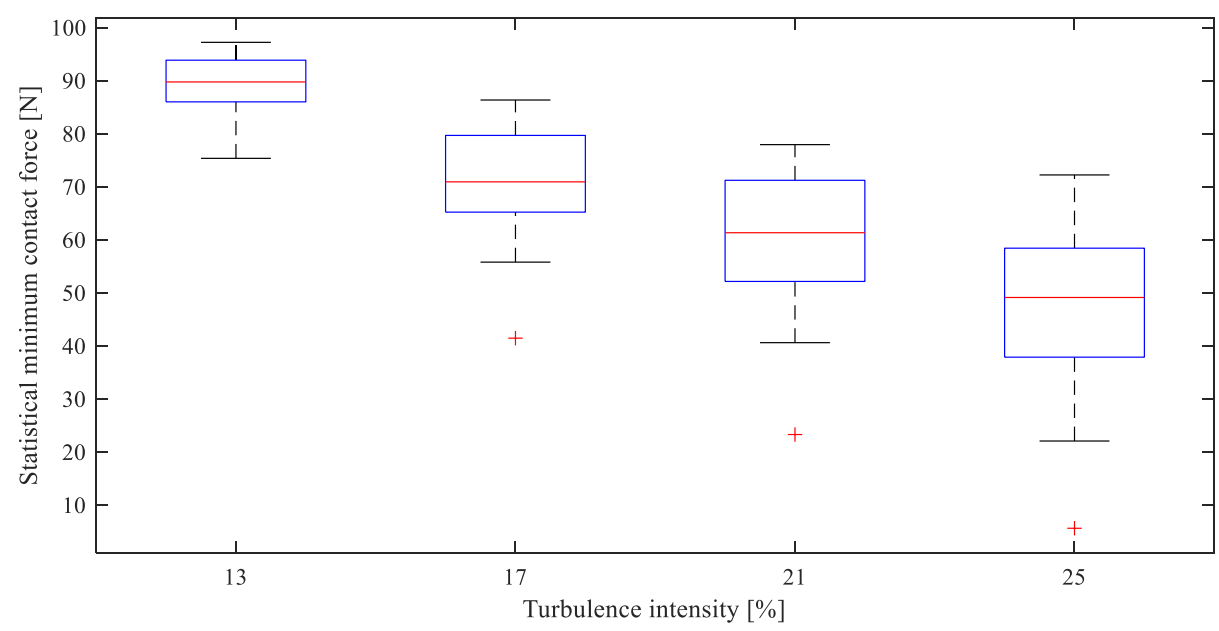

(a)

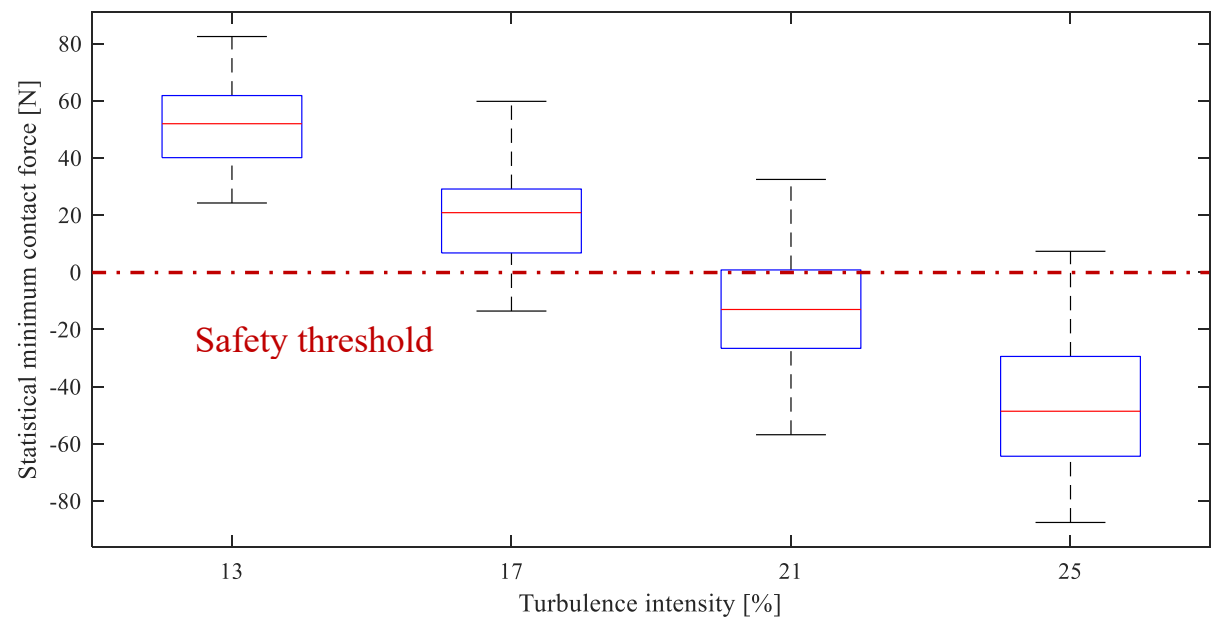

(b)

Figure 19. Boxplots of statistical minimum contact force with crosswind speed of (a) $20 \mathrm{~m} / \mathrm{s}$ and (b) $30 \mathrm{~m} / \mathrm{s}$ 


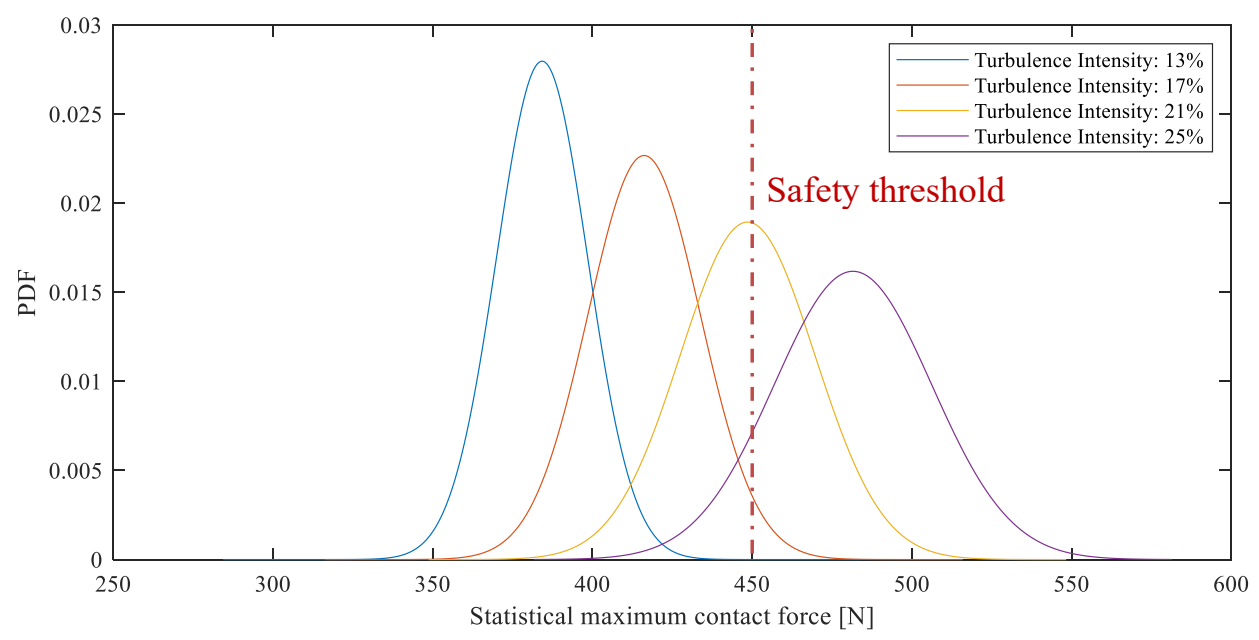

(a)

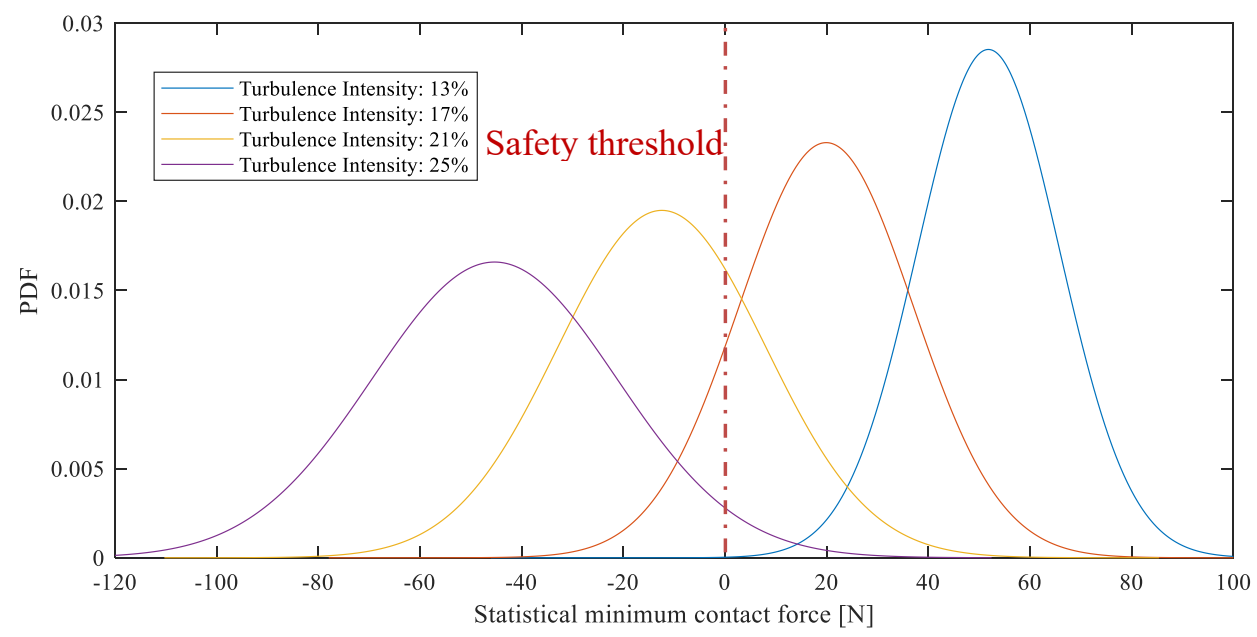

(b)

Figure 20. PDF of (a) statistical maximum contact force and (b) statistical minimum contact force with crosswind speed of $30 \mathrm{~m} / \mathrm{s}$

\subsection{Saftey Assessment}

The above analyses mainly focus on the assessment of current collection quality. In this section, the

operation safety caused by the crosswind is analysed. Generally, there are two safety issues for the pantograph-catenary interaction under crosswind. One is that the contact wire exceeds the working range of the pantograph head, which may cause the scraping of the pantograph collector. The other is the large uplift of the pantograph head, which may damage the catenary and cause the wire 
breakage. Here two indicators are adopted to facilitate the safety assessment. The first one is the maximum lateral deviation of contact point, which should be limited to $0.45 \mathrm{~m}$ to avoid the dewirement accident. The other is the maximum vertical uplift of pantograph head, which should be restricted within $0.2 \mathrm{~m}$ to avoid the damage of the catenary. Figure 21 (a) and (b) show the boxplot of maximum lateral deviation of contact point with crosswind speed of $20 \mathrm{~m} / \mathrm{s}$ and $30 \mathrm{~m} / \mathrm{s}$, respectively. It is seen that the maximum lateral deviation of contact point shows a sharp increase with the increase of the turbulence intensity. But all of them are within the safety range of $\pm 0.45 \mathrm{~m}$, which demonstrates that no dewirement accident can be caused by the crosswind for the analysed pantograph-catenary system. Figure 22 (a) and (b) show the boxplot of maximum vertical uplift of pantograph head with crosswind speed of $20 \mathrm{~m} / \mathrm{s}$ and $30 \mathrm{~m} / \mathrm{s}$, respectively. It is seen that all the maximum vertical uplift is always within the safety range of $0.2 \mathrm{~m}$ at a $20 \mathrm{~m} / \mathrm{s}$ crosswind speed. However, at a $30 \mathrm{~m} / \mathrm{s}$ crosswind speed, some maximum vertical uplifts can reach the ultimate limit of $0.2 \mathrm{~m}$ with the turbulence intensity of $21 \%$ and $25 \%$, indicating safety issues and deserve to be avoided in real-life operation.

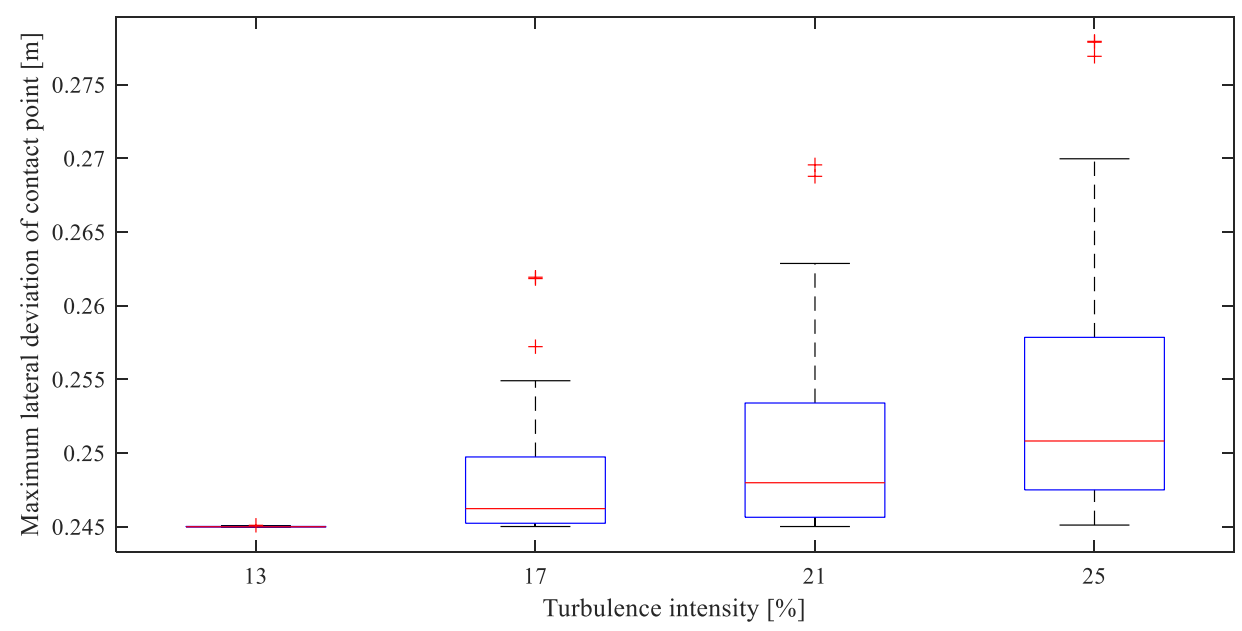

(a) 


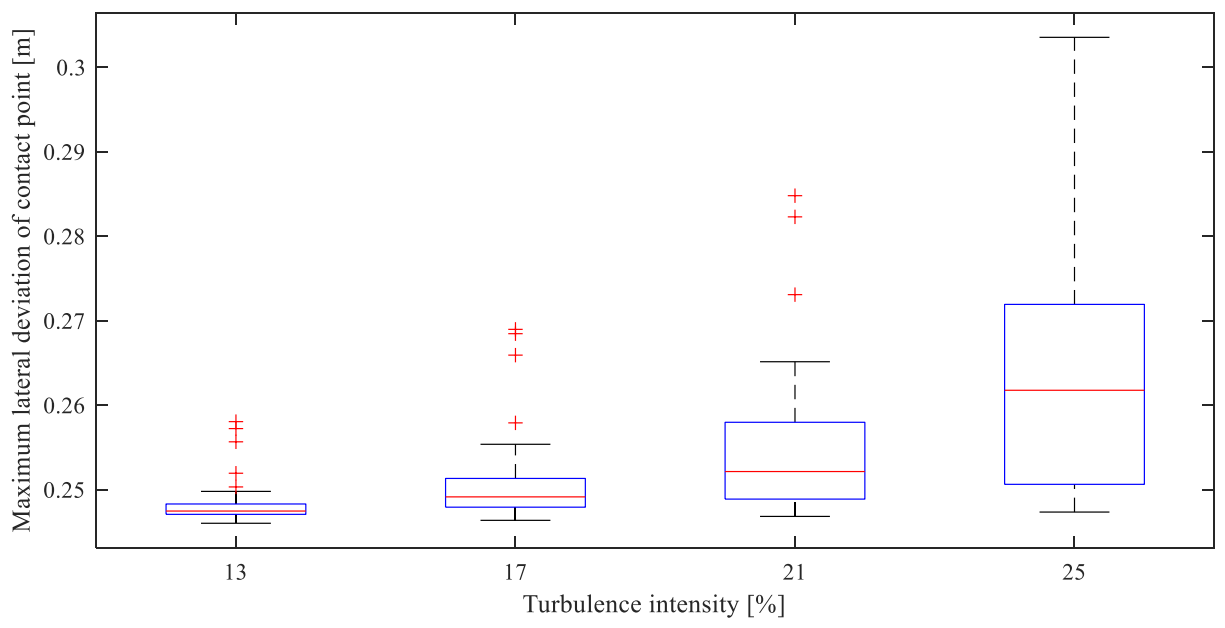

(b)

Figure 21. Boxplots of maximum lateral deviation of contact point with crosswind speed of (a) 20 $\mathrm{m} / \mathrm{s}$ and (b) $30 \mathrm{~m} / \mathrm{s}$

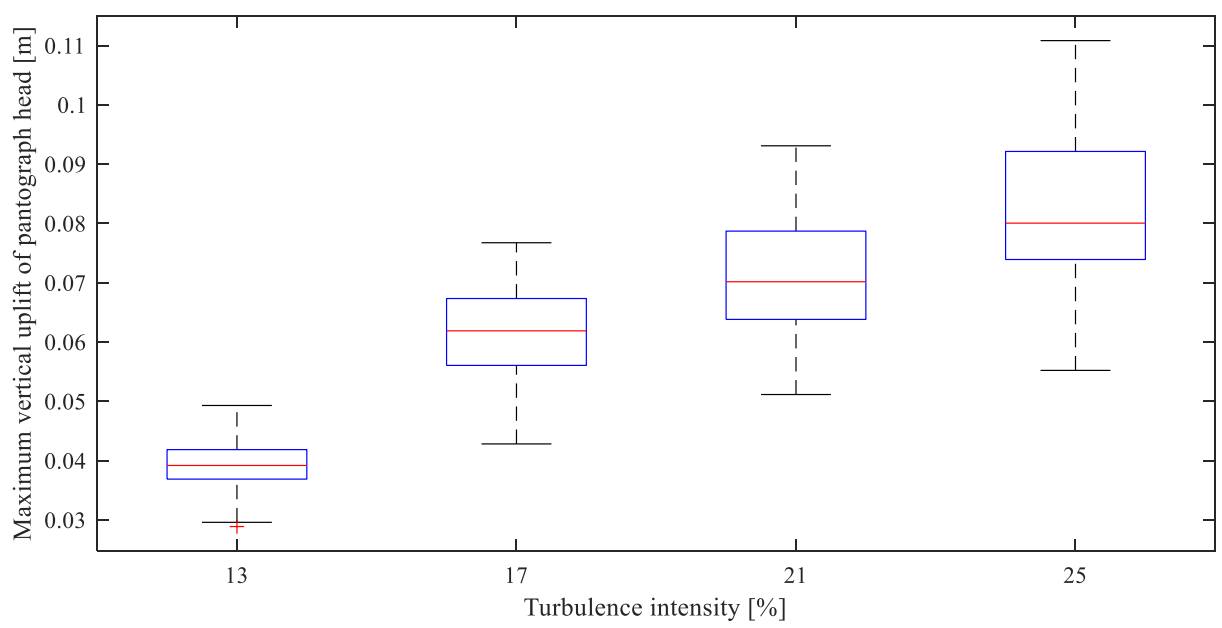

(a)

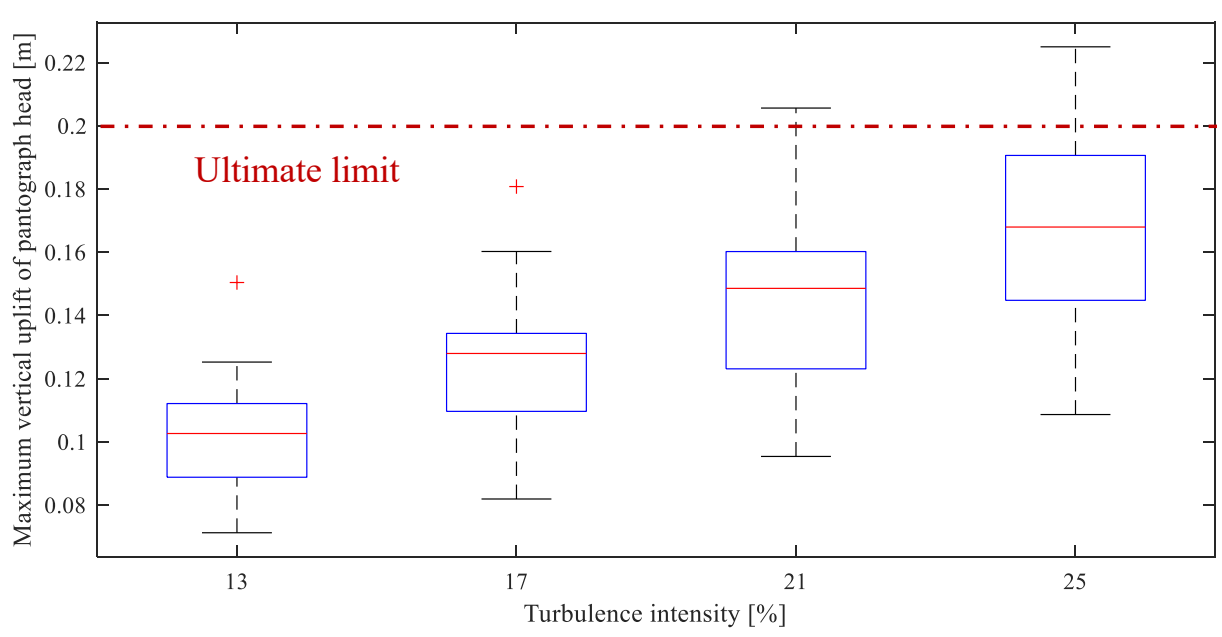


(b)

Figure 22. Boxplots of maximum vertical uplift of pantograph head with crosswind speed of (a) 20 $\mathrm{m} / \mathrm{s}$ and (b) $30 \mathrm{~m} / \mathrm{s}$

\section{Conclusions}

In this paper, the interaction performance of the pantograph-catenary is investigated under the crosswind with different turbulence intensities. The pantograph-catenary system of ChengduChongqing passenger special railway is adopted as the analysis object. The absolute nodal coordinate formulation is employed to build the catenary model, which can describe the nonlinearity of geometrical deformation and dropper slackness. The field measurement data collected from an inspection vehicle operating at $378 \mathrm{~km} / \mathrm{h}$ is used to validate the numerical accuracy. The stochastic wind field is constructed for the pantograph-catenary system based on the empirical spectrum. The wind load acting on the catenary is derived based on the quasi-steady theory. The CFD simulation is employed to calculate the lift and drag forces acting on each component of the pantograph. Based on multibody dynamics, the equivalent aerodynamic force used in the lumped-mass model is derived. The analysis of current collection quality indicates that the pantograph-catenary system has an acceptable performance at a crosswind of $20 \mathrm{~m} / \mathrm{s}$. But when the crosswind increases up to 30 $\mathrm{m} / \mathrm{s}$, some contact force statistics exceed the safety threshold with a turbulence intensity of more than $17 \%$. The operational safety analysis indicates that no dewirement issues should be concerned under the crosswind of $30 \mathrm{~m} / \mathrm{s}$ for the Chengdu-Chongqing passenger special railway. But the maximum uplift of pantograph head may exceed the ultimate limit with a turbulence intensity of more than $21 \%$. 


\section{Acknowledgement}

This work was supported in part by the Norwegian Railway directorate's funding, the National Natural Science Foundation of China (U1734202).

\section{Availability of data and materials}

The datasets generated during the current study are available from the corresponding author on reasonable request.

\section{Declarations}

\section{Conflict of interest}

The authors declare that they have no conflict of interest.

\section{References}

1. Zboinski, K., Golofit-Stawinska, M.: Investigation into nonlinear phenomena for various railway vehicles in transition curves at velocities close to critical one. Nonlinear Dyn. 98, 1555-1601 (2019). https://doi.org/10.1007/s11071-019-05041-2

2. Zboinski, K., Dusza, M.: Bifurcation analysis of 4-axle rail vehicle models in a curved track. Nonlinear Dyn. 89, 863-885 (2017). https://doi.org/10.1007/s11071-017-3489-y

3. Liu, Z., Song, Y., Han, Y., Wang, H., Zhang, J., Han, Z.: Advances of research on high-speed railway catenary. J. Mod. Transp. 26, 1-23 (2018). https://doi.org/10.1007/s40534-017-0148-4

4. Xu, L., Zhai, W.: Cross Wind Effects on Vehicle-Track Interactions: A Methodology for Dynamic Model Construction. J. Comput. Nonlinear Dyn. 14, 031003 (2019). https://doi.org/10.1115/1.4042142

5. Zhang, W., Zou, D., Tan, M., Zhou, N., Li, R., Mei, G.: Review of pantograph and catenary interaction. Front. Mech. Eng. 13, 311-322 (2018). https://doi.org/10.1007/s11465-018-0494-x

6. Huang, K., Liu, Z., Su, D., Zheng, Z.: A traction network chain-circuit model with detailed consideration of integrated grounding system in tunnel path. IEEE Trans. Transp. Electrif. 5, 535-551 (2019). https://doi.org/10.1109/TTE.2019.2914417

7. Kia, S.H., Bartolini, F., Mpanda-Mabwe, A., Ceschi, R.: Pantograph-catenary interaction model comparison. IECON Proc. (Industrial Electron. Conf. 1584-1589 (2010). https://doi.org/10.1109/IECON.2010.5675448

8. Xu, Z., Gao, G., Yang, Z., Wei, W., Wu, G.: An Online Monitoring Device for Pantograph 
Catenary Arc Temperature Detect Based on Atomic Emission Spectroscopy. ICHVE 2018 - 2018 IEEE Int. Conf. High Volt. Eng. Appl. 1-4 (2019). https://doi.org/10.1109/ICHVE.2018.8641866

9. Bruni, S., Ambrosio, J., Carnicero, A., Cho, Y.H., Finner, L., Ikeda, M., Kwon, S.Y., Massat, J.P., Stichel, S., Tur, M., Zhang, W.: The results of the pantograph-catenary interaction benchmark. Veh. Syst. Dyn. 53, 412-435 (2015). https://doi.org/10.1080/00423114.2014.953183

10. Ambrósio, J., Pombo, J., Pereira, M., Antunes, P., Mósca, A.: Recent Developments in Pantograph-Catenary Interaction Modelling and Analysis. Int. J. Railw. Technol. 1, 249-278 (2012). https://doi.org/10.4203/ijrt.1.1.12

11. Xu, Z., Song, Y., Liu, Z.: Effective Measures to Improve Current Collection Quality for Double Pantographs and Catenary Based on Wave Propagation Analysis. IEEE Trans. Veh. Technol. 69, 6299-6309 (2020). https://doi.org/10.1109/TVT.2020.2985382

12. Song, Y., Liu, Z., Xu, Z., Zhang, J.: Developed moving mesh method for high-speed railway pantograph-catenary interaction based on nonlinear finite element procedure. Int. J. Rail Transp. 7, 173-190 (2019). https://doi.org/10.1080/23248378.2018.1532330

13. Song, Y., Liu, Z., Lu, X.: Dynamic Performance of High-Speed Railway Overhead Contact Line Interacting with Pantograph Considering Local Dropper Defect. IEEE Trans. Veh. Technol. 69, 5958-5967 (2020). https://doi.org/10.1109/TVT.2020.2984060

14. Song, Y., Rønnquist, A., Nåvik, P.: Assessment of the High-Frequency Response in Railway Pantograph-Catenary Interaction Based on Numerical Simulation. IEEE Trans. Veh. Technol. 69, 10596-10605 (2020). https://doi.org/10.1109/TVT.2020.3015044

15. Chu, W., Song, Y., Duan, F., Liu, Z.: Development of steady arm damper for electrified railway overhead contact line with double pantographs based on numerical and experimental analysis. IET Electr. Syst. Transp. (2021). https://doi.org/10.1049/els2.12024

16. Zdziebko, P., Martowicz, A., Uhl, T.: An investigation on the active control strategy for a highspeed pantograph using co-simulations. Proc. Inst. Mech. Eng. Part I J. Syst. Control Eng. 233, 370-383 (2019). https://doi.org/10.1177/0959651818783645

17. Zhu, M., Zhang, S.Y., Jiang, J.Z., Macdonald, J., Neild, S., Antunes, P., Pombo, J., Cullingford, S., Askill, M., Fielder, S.: Enhancing pantograph-catenary dynamic performance using an inertance-integrated damping system. Veh. Syst. Dyn. (2021). https://doi.org/10.1080/00423114.2021.1884273

18. Wang, W., Liang, Y., Zhang, W., Iwnicki, S.: Effect of the nonlinear displacement-dependent characteristics of a hydraulic damper on high-speed rail pantograph dynamics. Nonlinear Dyn. 95, 3439-3464 (2019). https://doi.org/10.1007/s11071-019-04766-4

19. Wang, H., Núñez, A., Liu, Z., Song, Y., Duan, F., Dollevoet, R.: Analysis of the evolvement of contact wire wear irregularity in railway catenary based on historical data. Veh. Syst. Dyn. 56, 1207-1232 (2018). https://doi.org/10.1080/00423114.2017.1408919

20. Song, Y., Liu, Z., Ronnquist, A., Navik, P., Liu, Z.: Contact Wire Irregularity Stochastics and Effect on High-Speed Railway Pantograph-Catenary Interactions. IEEE Trans. Instrum. Meas. 69, 8196-8206 (2020). https://doi.org/10.1109/TIM.2020.2987457

21. Song, Y., Antunes, P., Pombo, J., Liu, Z.: A methodology to study high-speed pantographcatenary interaction with realistic contact wire irregularities. Mech. Mach. Theory. 152, 103940 (2020). https://doi.org/10.1016/j.mechmachtheory.2020.103940

22. Song, Y., Wang, Z., Liu, Z., Wang, R.: A spatial coupling model to study dynamic performance of pantograph-catenary with vehicle-track excitation. Mech. Syst. Signal Process. 151, 107336 
(2021). https://doi.org/10.1016/j.ymssp.2020.107336

23. Jafari, M., Hou, F., Abdelkefi, A.: Wind-induced vibration of structural cables. Nonlinear Dyn. 100, 351-421 (2020). https://doi.org/10.1007/s11071-020-05541-6

24. Song, Y., Liu, Z., Wang, H., Zhang, J., Lu, X., Duan, F.: Analysis of the galloping behaviour of an electrified railway overhead contact line using the non-linear finite element method. Proc. Inst. Mech. Eng. Part F J. Rail Rapid Transit. 232, 2339-2352 (2018). https://doi.org/10.1177/0954409718769751

25. Stickland, M.T., Scanlon, T.J., Craighead, I.A., Fernandez, J.: An investigation into the mechanical damping characteristics of catenary contact wires and their. Proc. Inst. Mech. Eng. Part F J. Rail Rapid Transit. 217, 63-72 (2001)

26. Song, Y., Liu, Z., Wang, H., Lu, X., Zhang, J.: Nonlinear analysis of wind-induced vibration of high-speed railway catenary and its influence on pantograph-catenary interaction. Veh. Syst. Dyn. 54, 723-747 (2016). https://doi.org/10.1080/00423114.2016.1156134

27. Pombo, J., Ambrosio, J., Pereira, M., Rauter, F., Collina, A., Facchinetti, A.: Influence of the aerodynamic forces on the pantograph-catenary system for high-speed trains. Veh. Syst. Dyn. 47, 1327-1347 (2009). https://doi.org/10.1080/00423110802613402

28. Song, Y., Zhang, M., Wang, H.: A Response Spectrum Analysis of Wind Deflection in Railway Overhead Contact Lines Using Pseudo-Excitation Method. IEEE Trans. Veh. Technol. 70, 11691178 (2021). https://doi.org/10.1109/TVT.2021.3054459

29. Sheng, F., Zhong, Z., Wang, K.H.: Theory and model implementation for analyzing line structures subject to dynamic motions of large deformation and elongation using the absolute nodal coordinate formulation (ANCF) approach. Nonlinear Dyn. 101, 333-359 (2020). https://doi.org/10.1007/s11071-020-05783-4

30. Pappalardo, C.M., Wang, T., Shabana, A.A.: Development of ANCF tetrahedral finite elements for the nonlinear dynamics of flexible structures. Nonlinear Dyn. 89, 2905-2932 (2017). https://doi.org/10.1007/s11071-017-3635-6

31. Shabana, A.A.: Definition of ANCF Finite Elements. J. Comput. Nonlinear Dyn. 10, (2015). https://doi.org/10.1115/1.4030369

32. BSI: BS EN 50317: Railway applications - Current collection systems - Requirements for and validation of measurements of the dynamic interaction between pantograph and overhead contact line. (2012)

33. BSI: BS EN 50317: Railway applications - Current collection systems - Requirements for and validation of measurements of the dynamic interaction between pantograph and overhead contact line. European Standards (EN), Brussels (2012)

34. Scanion, T.J., Stickland, M.T., Oldroyd, A.B.: An investigation into the attenuation of wind speed by the use of windbreaks in the vicinity of overhead wires. Proc. Inst. Mech. Eng. Part F J. Rail Rapid Transit. 214, 173-182 (2000). https://doi.org/10.1243/0954409001531298

35. Schlichting, H., Gersten, K.: Boundary-Layer Theory. Springer Berlin Heidelberg (2016)

36. Morfiadakis, E.E., Glinou, G.L., Koulouvari, M.J.: The suitability of the von Karman spectrum for the structure of turbulence in a complex terrain wind farm. J. Wind Eng. Ind. Aerodyn. 62, 237-257 (1996). https://doi.org/10.1016/S0167-6105(96)00059-1

37. Kiessling, F., Puschmann, R., Schmieder, A., Schneider, E.: Contact lines for electric railways, third edition. John Wiley \& Sons (2018)

38. European Committee for Electrotechnical Standardization: EN 50367. Railway applications - 
Current collection systems - Technical criteria for the interaction between pantograph and overhead line. European Standards (EN), Brussels (2016) 